Review

\title{
Lysine deacetylases and mitochondrial dynamics in neurodegeneration
}

\author{
Pedro Guedes-Dias, Jorge M.A. Oliveira* \\ REQUIMTE, Department of Drug Sciences, Faculty of Pharmacy, University of Porto, Porto, Portugal
}

\section{A R T I C L E I N F O}

\section{Article history:}

Received 30 December 2012

Received in revised form 30 March 2013

Accepted 2 April 2013

Available online 8 April 2013

\section{Keywords:}

Mitochondria

HDAC

Sirtuin

Mitochondrial dynamics

Biogenesis

Mitophagy

\begin{abstract}
A B S T R A C T
Lysine acetylation is a key post-translational modification known to regulate gene transcription, signal transduction, cellular transport and metabolism. Lysine deacetylases (KDACs), including classical KDACs (a.k.a. histone deacetylases; HDACs) and sirtuins (SIRTs), are emerging therapeutic targets in neurodegeneration. Given the strong link between abnormal mitochondrial dynamics and neurodegenerative disorders (e.g. in Alzheimer, Parkinson and Huntington diseases), here we examine the evidence for KDAC-mediated regulation of mitochondrial biogenesis, fission-fusion, movement and mitophagy. Mitochondrial biogenesis regulation was reported for SIRT1, SIRT3, and class IIa KDACs, mainly via PGC-1alpha modulation. SIRT1 or SIRT3 overexpression rescued mitochondrial density and fission-fusion balance in neurodegeneration models. Mitochondrial fission decreased with pan-classical-KDAC inhibitors and increased with nicotinamide (pan-sirtuin-inhibitor/activator depending on concentration and $\mathrm{NAD}^{+}$conversion). Mitochondrial movement increased with HDAC6 inhibition, but this is not yet reported for the other tubulin deacetylase SIRT2. Inhibition of HDAC6 or SIRT2 was reported neuroprotective. Mitophagy is assisted by the HDAC6 ubiquitin-binding and autophagosome-lysosome fusion promoting activities, and was also associated with SIRT1 activation. In summary, KDACs can potentially modulate multiple components of mitochondrial dynamics, however, several key points require clarification. The SIRT1-biogenesis connection relies heavily in controversial caloric restriction (CR) regimes or CR-mimetic drugs, and appears cell-type dependent, recommending caution before linking SIRT1 activation with general neuroprotection. Future studies should clarify mitochondrial fission-fusion regulation by KDACs, and the interplay between HDAC6 and SIRT1 in mitophagy. Also, further studies are required to ascertain whether HDAC6 inhibition to enhance mitochondrial trafficking does not compromise autophagy or clearance of misfolded proteins in neurodegenerative disorders.
\end{abstract}

(c) 2013 Elsevier B.V. All rights reserved.

\section{Introduction}

\subsection{An extended phenotype for lysine acetylation}

Acetylation at the $\varepsilon$-amino group of lysines is a reversible posttranslational modification (PTM), crucial for regulating the function of multiple proteins [1,2]. Lysine acetyltransferases (KATs) and lysine deacetylases (KDACs) act in concert to modulate the acetylation status of their targets. Since lysine acetylation prevents positive charges from forming on the amino group, this PTM strongly influences protein electrostatic properties [3]. The functional consequences vary

Abbreviations: AD, Alzheimer's disease; CR, caloric restriction; DRG, dorsal root ganglion; Drp1, dynamin-related protein 1; HAT, histone acetyltransferase; HD, Huntington's disease; HDAC, histone deacetylase; Hsp90, heat shock protein 90; KAT, lysine acetyltransferases; KDAC, lysine deacetylase; Mff, mitochondrial fission factor; Mfn, mitofusin; MIEF1, mitochondrial elongation factor 1; mtDNA, mitochondrial DNA; NRF, nuclear respiratory factor; OPA1, optic atrophy 1; PD, Parkinson's disease; POMC, proopiomelanocortin; PTM, post-translational modification; Tfam, mitochondrial transcription factor A

* Corresponding author at: Department of Drug Sciences, Faculty of Pharmacy, University of Porto, Rua Jorge Viterbo Ferreira, 228, 4050-313 Porto, Portugal. Tel.: + 351220428 610; fax: + 351226093390 .

E-mail address: jorgemao@ff.up.pt (J.M.A. Oliveira). with the relative position of specific lysine residues within the target protein, and may manifest as increases as well as decreases in activity, affinity, stability, or in protein-protein interaction [3,4].

Histones were the first substrates identified for eukaryotic KATs and KDACs, explaining their common designation as histone acetyltransferases (HATs) and deacetylases (HDACs), respectively [1]. Histone acetylation strongly correlates with gene transcription, likely by relaxing chromatin and facilitating access to the transcription machinery. Moreover, acetylation of specific lysine residues may directly serve as recognition sites for transcription factors [5]. Still, when considering KDAC non-histone targets, particularly transcription factors, it can no longer be generalized that increased acetylation stimulates transcription. Indeed, acetylation of transcription factors may increase or decrease their DNA binding affinity depending on whether the specific acetylation sites fall directly adjacent or within the DNA-binding domain, respectively [4]. Thus, KATs' and KDACs' effects on acetylation and transcription provide a versatile mechanism for coupling extracellular signals with the genome.

Non-histone targets regulated by lysine acetylation are mostly comprised by transcription factors, but the growing list also includes other key cellular proteins, such as $\alpha$-tubulin, importin $\alpha$, heat shock protein 90 (Hsp90), and cortactin, among others [3,6]. Thus, lysine 
acetylation plays import regulatory roles not only in transcription, but also in signal transduction and cellular transport processes. Further, lysine acetylation is a key metabolic regulatory signal, particularly at the level of mitochondria [7].

KDACs in particular have received much attention not only for their physiological roles, but also for their involvement in disease states and, consequently, for being a therapeutic target [8]. In addition to cancer, neurodegenerative disorders are also under the scope of possible therapy with drugs targeting KDACs $[9,10]$. Thus, considering the emerging role of abnormal mitochondrial dynamics in the pathogenesis of neurodegenerative disorders [11], in this review we examine the hypothesis that the extended phenotype of KDAC activity involves a modulation of mitochondrial dynamics that may have therapeutic implications in neurodegeneration. We start by briefly addressing key aspects of KDACs, followed by focused analyses on how KDAC modulation impacts 4 divisions of mitochondrial dynamics: biogenesis, fission-fusion, movement, and mitophagy; and how such dynamics are affected in neurodegenerative diseases.

\section{KDACs: classes and functions}

The mammalian KDAC superfamily currently holds eighteen members. A core division based on homology with yeast KDACs separates 'classical HDACs' (zinc-dependent, Rpd3/Hda1 homologues) from 'sirtuins' (NAD ${ }^{+}$-dependent, Sir2 homologues). Another division establishes four classes based on phylogenetic analysis and sequence homology. Classes I, II and IV comprise classical HDACs (with class II further divided into IIa and IIb), while class III comprises sirtuins [12].

Class I KDACs (HDAC1, 2, 3, and 8) are predominantly nuclear and widely expressed in most tissues, except for HDAC8 that is confined to smooth muscle where it associates with $\alpha$-actin and is essential for contractility [13]. HDAC1 and 2 are highly homologous and act together as the catalytic subunits of major transcriptional repressor complexes such as Sin3, NuRD/NRD/Mi2, and CoREST [14]. This collaborative spirit of KDACs [15] also applies to HDAC3, which is responsible for the deacetylase activities associated with Class II KDACs, working together in a repressor complex with SMRT/N-CoR [16]. Class II KDACs display tissue-specific expression patterns, being highly expressed in the brain, heart, and muscle. Class Ila contains HDAC4, 5, 7, and 9. While full-length HDAC9 remains in the nucleus, HDAC4, 5, 7 and a splice variant of HDAC9 (MITR) shuttle between the nucleus and cytosol. Phosphorylation and binding to 14-3-3 proteins anchor these HDACs in the cytosol, whereas dephosphorylation releases them to return to the nucleus [9]. Class IIb consists of HDAC6 and 10, both primarily cytosolic. HDAC6 is unique in containing a C-terminal ubiquitin-binding domain and two functional deacetylase domains. Cytosolic HDAC6 deacetylates tubulin, cortactin and HSP90, regulating axonal trafficking, cell motility and degradation of misfolded proteins. HDAC6 can also shuttle to the nucleus to regulate transcription, with its activity and subcellular localization being regulated by acetylation [17]. HDAC10 possesses a unique leucine-rich domain, interacts with HDAC3, and represses transcription when tethered to a promoter [18]. Class IV consists only of HDAC11, a predominantly nuclear KDAC that regulates immune tolerance [19].

Sirtuins (Class III KDACs) comprise seven mammalian enzymes, SIRT1-7. Their deacetylation reaction consumes the cofactor NAD ${ }^{+}$ while generating nicotinamide plus a mixture of $2^{\prime}$ and 3 '-O-acetylADP-ribose [20]. SIRT1 is present in the nucleus, deacetylating histones and several transcription factors. SIRT1 deacetylates and activates the transcriptional co-activator PGC- $1 \alpha$, a master regulator of mitochondrial biogenesis [21]. SIRT1 was reported predominantly cytosolic in the adult brain [22], while PGC1- $\alpha$ may also reside in the cytosol being directed to the nucleus by stimuli-associated PTMs [23,24]. SIRT2 is primarily cytosolic but may also occur in the nucleus where it preferentially deacetylates histone H4K16 [25]. SIRT2 shares $\alpha$-tubulin deacetylase activity with HDAC6 [26], and has been suggested as the main microtubule deacetylase in mature neurons [27], although it was also reported that SIRT2 genetic reduction or ablation has no effect on the acetylation of $\alpha$-tubulin or H4K16 in mouse brain [28]. Additionally, SIRT2 is reported to deacetylate the transcription factor p65 in the cytosol, thus regulating expression of NF-KB-dependent genes [29]. SIRT3, 4 and 5 are also called 'mitochondrial sirtuins' given their subcellular location. SIRT3 is the main deacetylase in the mitochondria, where it regulates oxidative phosphorylation, protein synthesis and multiple metabolic pathways. The other two mitochondrial sirtuins show weak deacetylase activity, with SIRT5 exhibiting pronounced demalonylase and desuccinylase activity, and the primary activity of SIRT4 remaining elusive [7]. SIRT6 is a nuclear histone H3K9 deacetylase with a key role in telomere maintenance and DNA repair [30]. SIRT7 is a selective histone H3K18 deacetylase [31] and an activator of RNA polymerase I transcription [32].

\section{The modulation of KDAC activity}

Physiological modulation of KDACs may occur at multiple steps of their life cycle, including transcription, pos-transcriptional and proteolytic processing. Additionally, protein-protein interactions, co-factor availability, and several PTMs allow dynamic activity control. Most KDACs require integration in multi-protein complexes and nuclear localization in order to repress transcription. Thus, the activity of such KDACs predictably decreases upon interference with complex assembly/stability, reduced availability of interacting proteins (e.g. N-CoR for HDAC3), or enhanced nuclear export plus cytosolic retention (e.g. class II KDACs). Conversely, for KDACs acting primarily in the cytosol (e.g. HDAC6 and SIRT2), cytosolic retention can increase their activity [14].

PTM by phosphorylation may either increase (e.g. HDAC1) or decrease (e.g. HDAC8) class I enzymatic activity, while regulating class II subcellular localization via binding to 14-3-3 proteins [14]. In turn, PTM by acetylation of the catalytic domain and C-terminal region strongly diminishes HDAC1 enzymatic activity [33] and, similarly, p300mediated SIRT2 acetylation reduces its deacetylase activity [34]. Also, 'site B'-acetylation decreases HDAC6 tubulin- but not histonedeacetylase activity (in vitro), although in situ histone acetylation should decrease since the same PTM reduces HDAC6 nuclear import [17]. Concerning co-factor availability, the NAD ${ }^{+}: \mathrm{NADH}$ ratio links cellular metabolic status to class III KDACs' activity [14], whereas zinc is critical for other KDACs' catalytic activity. Finally, while proteolytic degradation of KDACs or their co-activators predictably diminishes their activity, specific proteolytic processing may be required for full deacetylase activity (e.g. mitochondrial SIRT3 [35]). Thus, multiple physiological processes modulate KDAC activity, and some have already assisted drug development.

Pharmacological KDAC modulators are predominantly inhibitors, with different structural requirements for acting on classical KDACs vs. sirtuins. Few activators have been reported, except for SIRT1 where several presumed activators have been synthesized (inc. SRT1720, SRT2183 and SRT1460), but there is now evidence that these compounds and resveratrol are not direct SIRT1 activators [36], albeit recent data suggests that at least some of the physiological effects of these type of compounds may occur by "assisted allosteric activation" [37]. Most classical KDACs' inhibitors lack isoform-selectivity as they act by chelating zinc in the catalytic domain. Differential interaction with amino acid residues at the entry of the KDAC active site, and the mimicking of natural substrates may account for isoform-selective inhibitors, but currently little is known about their structure-activity relationships [38-40]. Most sirtuin inhibitors prevent NAD ${ }^{+}$from binding the catalytic domain by blocking the required nicotinamide binding site. Alternatively, some sirtuin inhibitors compete with the acetylated peptide substrate for its binding site in the catalytic domain [20].

Examples of commonly used KDAC inhibitors of particular relevance for this review are as follows. Pan-(classical)-KDAC inhibitors with nanomolar $\mathrm{IC}_{50}$ include the hydroxamate derivatives trichostatin $\mathrm{A}$ 
and vorinostat (SAHA) [41]. The short chain fatty acids butyrate and valproate are class I and Ila inhibitors in the micro to millimolar range [38]. Entinostat (MS-275) is an HDAC1-selective inhibitor [41], whereas tubacin and tubastatin A are HDAC6-selective inhibitors, respectively, with 350- and 1000-fold selectivity over HDAC1 [42]. Concerning sirtuins, nicotinamide is often used as a pan-sirtuin inhibitor, whereas EX527 and AGK2 are described as selective SIRT1 and SIRT2 inhibitors, respectively [20].

\section{Biogenesis}

Mitochondria are continuously renewed by the physiological equilibrium between biological generation (biogenesis) and selective degradation through autophagy (mitophagy). Increasing the cellular mitochondrial mass is biologically expensive and a long-term adaptive response. As such, transient energy demands are met by changes in expression of subsets of genes, regulators, or increases in mitochondrial function. Physiological states such as endurance training, caloric restriction, and long-term cold exposure (leading to adaptive thermogenesis) are reported to promote mitochondrial biogenesis [43,44].

A complex network of nuclear and mitochondrial transcription factors orchestrate mitochondrial biogenesis, a process in which the PGC-1 family of transcriptional coactivators plays master regulatory roles. PGC-1 coactivators integrate signals and coordinate biological responses allowing cellular adaptation to changes in energy demand, including increases in mitochondrial biogenesis, respiration and metabolism [45]. PGC- $1 \alpha$ coactivates nuclear respiratory factors (NRFs), which control expression of nuclear-encoded mitochondrial structural proteins [46]. The resulting preproteins must be imported, processed and correctly assembled in mitochondria, a complex process involving finely tuned posttranscriptional mechanisms and the target of rapamycin (TOR) signaling pathway [47]. PGC- $1 \alpha$-coactivated NRFs also regulate expression of mitochondrial transcription factor A (Tfam), a nuclear-encoded transcription factor crucial for replication, transcription, and maintenance of mitochondrial DNA (mtDNA) [48].

\subsection{KDACs and mitochondrial biogenesis}

The link between KDACs and mitochondrial biogenesis stems primarily from the modulation of PGC- $1 \alpha$ by transcriptional or posttranslational mechanisms (Fig. 1; Table 1). PGC-1 $\alpha$ transcription is promoted by myocyte-enhancer factor-2 (MEF2) and diminished by class Ila KDACs that repress MEF2 activity. Both class IIa KDACs and MEF2 transcription factors are highly expressed in muscle and brain, and phosphorylation of these KDACs promotes their nuclear export, releasing MEF2 to activate PGC- $1 \alpha$ transcription [49]. Consistently, pan-KDAC inhibitors (trichostatin A and valproate) upregulated PGC- $1 \alpha$ in neuroblastoma cells [50]. Concerning posttranslational mechanisms, PGC-1 $\alpha$ acetylation by the GCN5 acetyltransferase reduces its transcriptional activity [51], whereas deacetylation by SIRT1 activates PGC-1 $\alpha$ [21]. Interestingly, SIRT1 converges with AMP-activated kinase (AMPK) to activate PGC-1 $\alpha$; AMPK increases levels of the SIRT1 cofactor NAD + [52] and activates PGC- $1 \alpha$ by phosphorylation [53]. Further, these posttranslational modifications of PGC- $1 \alpha$ activity also promote its own transcription via an autoregulatory feedforward loop [54].

The relationship between SIRT1 and mitochondrial biogenesis has been mostly explored in the context of caloric restriction $(C R)-a$ regime reportedly capable of extending life span by inducing SIRT1 expression [55]. However, studies reporting increased mitochondrial biogenesis following $\mathrm{CR}$ [56-58] were challenged by a recent study showing no increases in mitochondrial structural proteins in several rat tissues including the brain [59]. Notwithstanding, CR lacks the selectivity required to scrutinize the pathways linking SIRT1 and mitochondrial biogenesis. Alternatively, compounds designated as SIRT1 activators or "CR mimetic drugs" have been tested and reported to improve mitochondrial function and enhance mitochondrial biogenesis and function [60-62]. Still, there is now evidence that such compounds (inc. resveratrol, SRT1720, SRT2183, and SRT1460) do not directly activate SIRT1 [36], but see also the recently suggested "assisted allosteric activation" in [37]. Attention has thus turned to AMPK, the SIRT1 partner in activating PGC- $1 \alpha$ [52]. Some authors argue that AMPK is upstream of SIRT1 in the cascade of resveratrol metabolic effects, including mitochondrial biogenesis. Accordingly, AMPK-deficient mice presented a faulty response to resveratrol and AMPK was considered the main resveratrol target [63]. More indirectly, resveratrol was reported to inhibit cAMP-degrading phosphodiasterases, increasing cAMP levels and igniting a cascade that activates AMPK [64]. In both studies, upstream AMPK activation led to NAD + increases explaining indirect SIRT1 activation by resveratrol $[63,64]$. In contrast, a recent study positions AMPK downstream of SIRT1, provided that resveratrol is used in "moderate" doses [65]. In that study, authors argue that while high doses of resveratrol may activate AMPK directly, moderate doses increase mitochondrial biogenesis in a SIRT1-dependent manner, upstream of AMPK activation. Thus, resveratrol indirect activation of AMPK was reported SIRT1-dependent, via deacetylation of the AMPK kinase LKB1. Significantly, both high and moderate doses of resveratrol failed to increase mitochondrial biogenesis in SIRT1 knockouts [65].

\subsection{Neuronal mitochondrial biogenesis and KDAC modulation}

The effects of KDAC modulation on neuronal mitochondrial biogenesis have been scarcely explored (the wealth of current data on these signaling pathways pertains to non-neuronal cells). As far as we could find, KDAC activation in neurons (or neuroblastoma cells) has been tested only for SIRT1, by means of overexpression or using compounds such as resveratrol (with doubtful SIRT1 specificity [36]). Conversely, the effects of KDAC inhibition have been tested using SIRT1 deletion, the SIRT1 inhibitor EX-527, and pan-KDAC inhibitors. Such data are reviewed below, identifying the models and with the proviso that neuroblastoma cell lines can behave quite differently from post-mitotic neurons.

In neuroblastoma cells (Neuro2a), resveratrol was reported to increase mitochondrial biogenesis markers through AMPK activation [66]. Authors excluded SIRT1 involvement in AMPK activation in neuroblastoma or primary neurons since neither SIRT1 inhibitors (sirtinol, splitomycin, and nicotinamide) nor SIRT1 deletion attenuated AMPK activation. Interestingly, their study suggests that resveratrol effects are neuron-type-dependent. According to their results, AMPK phosphorylation in dorsal root ganglion (DRG) neurons is primarily dependent on LBK1 activity, whereas in cortical neurons it also requires CamKKB [66]. Still, their study suggests that LKB1 activity is SIRT1 independent, which is compatible with some studies [64], but contrasts with others reporting SIRT1-dependence [65,67]. Such diverse findings might be explained by cell-type-dependent variations on these signaling pathways. Still, regardless of whether resveratrol has multiple targets that might modulate mitochondrial biogenesis, it is important to verify if directly targeting SIRT1 activity suffices for altering mitochondrial biogenesis in neurons.

In primary cortical neurons, SIRT1 overexpression or GCN5 acetyltransferase silencing increased mitochondrial density in cell bodies and axons [68]. Further, increased mitochondrial biogenesis by SIRT1 was critically dependent on PGC- $1 \alpha$, but independent from AMPK. Also, authors showed that SIRT1 effects resulted from deacetylating PGC- $1 \alpha$ and increasing its transcriptional activity [68].

In vivo SIRT1 inhibition (with EX-527) increased mitochondrial density in hypothalamic proopiomelanocortin (POMC) neurons, without affecting indexes of mitochondrial morphology [69]. This was interpreted as an adaptive response to decreased inhibitory tone on POMC neurons [69]. Conceivably, the heightened activity of uninhibited POMC neurons consumes ATP, increasing the AMP:ATP ratio and activating AMPK-dependent mitochondrial biogenesis via PGC- $1 \alpha$ phosphorylation.

Taken together, these findings suggest that increased SIRT1 activity promotes neuronal mitochondrial biogenesis [68], but this may also 


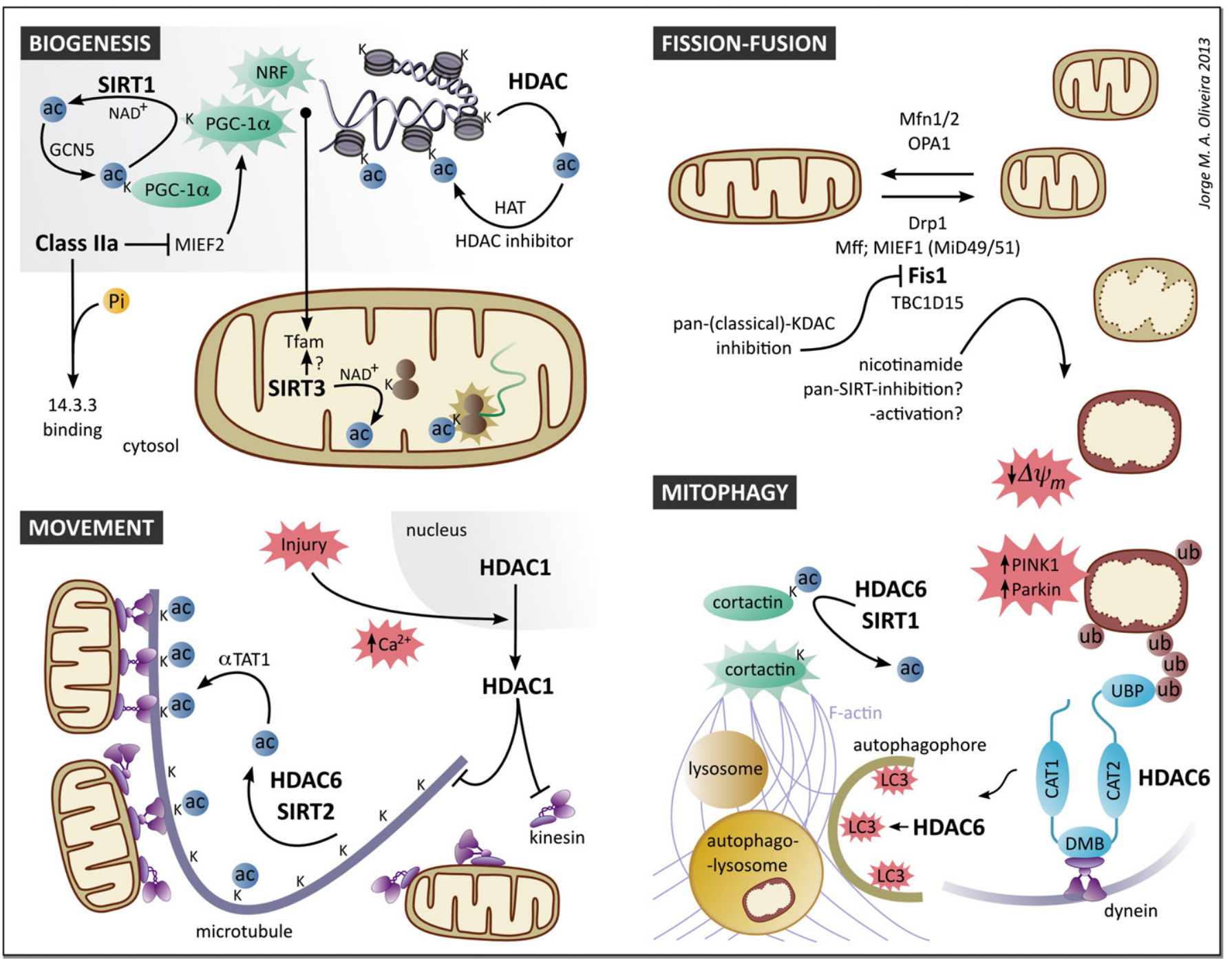

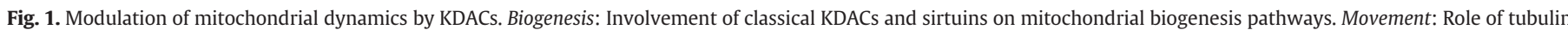

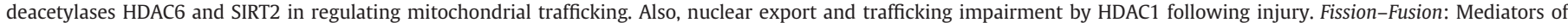

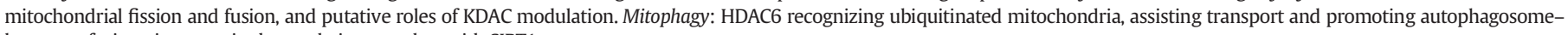
lysosome fusion via cortactin deacetylation together with SIRT1.

occur without SIRT1 involvement [66], and even following SIRT1 inhibition, at least in specific neuronal populations [69]. Significantly, pan-inhibition of KDACs (trichostatin A and valproate) in neuroblastoma cells was reported to upregulate PGC- $1 \alpha$ [50], and thus may evoke mitochondrial biogenesis. Clearly, more studies are required to elucidate how the AMPK-SIRT1-PGC- $1 \alpha$ axis, and other KDACs work in neurons to modulate mitochondrial biogenesis. Current evidence suggests that SIRT1 activity and signaling are highly cell-type dependent, thus advising caution before establishing links between SIRT1 activation and general neuroprotection.

\subsection{Mitochondrial biogenesis in neurodegeneration}

Multiple neurodegenerative disorders have been associated with abnormal mitochondrial biogenesis. Decreases in PGC-1 $\alpha$ levels were reported in the context of Huntington (HD), Alzheimer (AD), and Parkinson's (PD) diseases as well as in spinal and bulbar muscular atrophy, whereas PGC- $1 \alpha$ overexpression was protective in several in vitro and in vivo disease models [70], although a recent study evidenced that sustained PGC- $1 \alpha$ overexpression was deleterious to dopaminergic neurons in vivo [71]. Mitochondria number was found decreased in HD patients' brains, together with decreased levels of PGC- $1 \alpha$, Tfam and mitochondrial cytochrome $c$ oxidase subunit II [72]. Moreover, PGC-1 $\alpha$ null mice presented neurodegenerative lesions predominantly in the striatum [73], a particularly vulnerable region in HD [74]. Mitochondria number was also decreased in primary neurons cultured from $\mathrm{AD}$ mice [75] and in $\mathrm{AD}$ patients' brains [76] together with decreased expression of PGC- $1 \alpha$, NRF1, NRF2a/2b and Tfam [77]. In PD patients, both PGC- $1 \alpha$ and NRF-1 mRNA were decreased in the substantia nigra and striatum [78]. Furthermore, some PGC- $1 \alpha$ polymorphisms have been tentatively associated with risk or age of onset of PD [79] and HD [80-82], although population stratification may have influenced result interpretation [83].

PGC- $1 \alpha$ thus represents an interesting target to rescue mitochondrial biogenesis in neurodegeneration models, yet relatively unexplored in what concerns KDAC modulation. Significantly, one study reported that SIRT1 overexpression restored mitochondrial density and increased survival both in PD and HD neuronal models, respectively, expressing A53T $\alpha$-synuclein and $120 \mathrm{Q}$ huntingtin [68]. Further studies are required to clarify SIRT1 and other KDACs' potential as mitochondrial biogenesis modulators in neurons and more specifically in neurodegenerative disorder models.

Recently, another sirtuin (SIRT3) was reported to stimulate mitochondrial biogenesis [84] (Fig. 1). Silencing of the mitochondrial sirtuin 


\begin{tabular}{|c|c|c|c|c|c|}
\hline KDAC isoform & Model & Activity modulation method & Main findings & Comments & Ref. \\
\hline \multirow{3}{*}{ SIRT1 } & \multirow[b]{2}{*}{ C2C12 myoblasts } & $10 \mu \mathrm{M} \mathrm{EX}-527(24 \mathrm{~h})$ & Decreased mtDNA & \multirow{3}{*}{$\begin{array}{l}\text { Suggests that SIRT1 Is required for AMPK activation and } \\
\text { the beneficial efects of resveratrol on mitochondrial } \\
\text { function, including enhanced mitochondrial biogenesis. }\end{array}$} & \multirow{3}{*}[65]{} \\
\hline & & ShSIRT1 & $\begin{array}{l}\text { Decreased mtDNA. Unaltered PGC- } 1 \alpha, \text { NRF-1, NRF-2, COX5 } \beta \\
\text { and ATP5 } \alpha \text { mRNA. }\end{array}$ & & \\
\hline & SIRT1-Tg mice skeletal muscle & Constitutive SIRT1 expression & Increased mtDNA. Increased PGC-1 $1 \alpha$, NRF-1 and Tfam mRNA. & & \\
\hline \multirow{3}{*}{ SIRT1 } & \multirow{3}{*}{ Mice with heart-specific SIRT1 overexpression } & Low SIRT1 expression & $\begin{array}{l}\text { Unaltered mitochondria number per cardiomyocyte area. } \\
\text { Unaltered PGC- } 1 \alpha, \text { NRF-1 and Tfam mRNA. }\end{array}$ & \multirow{3}{*}{$\begin{array}{l}\text { Reports that constitutive SIRT1 overexpression in the } \\
\text { heart impairs mitochondria and reduces cardiac } \\
\text { function. }\end{array}$} & \multirow{3}{*}{186} \\
\hline & & Moderate SIRT1 expression & $40 \%$ decrease in NRF-1 mRNA. & & \\
\hline & & High SIRT1 expression & $50 \%$ decrease in NRF-1 mRNA. & & \\
\hline \multirow[t]{2}{*}{ SIRT1 } & \multirow[t]{2}{*}{ Rabbit primary renal proximal tubule cells } & $10 \mu \mathrm{M} \mathrm{SRT} 1720(24 \mathrm{~h})$ & $\begin{array}{l}\text { Increased PGC-1 } \alpha \text { expression. } 50 \% \text { decrease in aceylated-PGC- } \\
1 \alpha \text {. Unaltered PGC- } 1 \alpha \text { mRNA levels. Increased (3.5x) mtDNA } \\
\text { content. }\end{array}$ & \multirow{2}{*}{$\begin{array}{l}\text { Suggests that SIRT1 activation induces mitochondrial } \\
\text { biogenesis through an AMPK-independent pathway, } \\
\text { protecting mitochondria and renal proximal tubule cells } \\
\text { against acute oxidant injury. }\end{array}$} & \multirow[t]{2}{*}[61]{} \\
\hline & & $100 \mu \mathrm{M}$ Nicotinamide & $\begin{array}{l}\text { Unaltered mtDNA content. Nicotinamide pre-treatment } \\
\text { prevents SRT1720-induced mtDNA content increase. }\end{array}$ & & \\
\hline SIRT1 & Mouse POMC neurons & $1.5 \mathrm{nmol} /$ mouse EX-527 (i.c.v) & Increased mitochondrial density and area in the soma. & $\begin{array}{l}\text { SIRT1 blocked the recruitment of inhibitory synapses } \\
\text { onto POMC neurons, increasing their activity. Suggests } \\
\text { that SIRT1 activation in NPY/Agrp neurons is essential } \\
\text { for physiological adaptation to negative energy } \\
\text { balance. }\end{array}$ & [69] \\
\hline \multirow{4}{*}{ SIRT1 } & \multirow[t]{2}{*}{ Rat primary cortical neurons } & SIRT1 overexpression & $\begin{array}{l}\text { Increased mitochondrial density. SIRT1 increased PGC-1 } \alpha \\
\text { transcriptional activity but not PGC- } 1 \alpha \text { transcription. }\end{array}$ & \multirow{4}{*}{$\begin{array}{l}\text { Reports the regulation of mitochondrial density in } \\
\text { neurons by PGC- } 1 \alpha \text { and PGC- } 1 \beta \text {, and that increased } \\
\text { PGC- } 1 \alpha \text { or SIRT } 1 \text { expression protects against mutant } \alpha \text { - } \\
\text { synuclein or huntingtin. }\end{array}$} & \multirow{4}{*}{ [68] } \\
\hline & & SIRT1 $1^{\mathrm{G} 261 \mathrm{~A}}$ expressiont & Unaltered mitochondrial density. & & \\
\hline & Cortical neurons expressing mutant $\alpha$-synuclein & SIPT1 ourereynrecsion & Peyertc mitochondrizl dencity decrezs & & \\
\hline & Cortical neurons expressing mutant huntingtin & SIR11 overexpression & Reverts mitochondrial density decrease. & & \\
\hline SIRT1 & C2C12 myotubes & ShSIRT1 & Unaltered PGC- $1 \alpha$ protein levels. & $\begin{array}{l}\text { Reports that resveratrol benefits mice with diet- } \\
\text { induced obesity; SIRT1 activation by resveratrol and } \\
\text { SIRT1-dependent PGC-1 } \alpha \text { activation. }\end{array}$ & {$[60]$} \\
\hline \multirow{5}{*}{ SIRT3 } & \multirow{3}{*}{$\mathrm{C} 2 \mathrm{C} 12$ cells } & SIRT3 overexpression & Decreased mitochondrial protein synthesis & \multirow{5}{*}{$\begin{array}{l}\text { Proposes that matrix SIRT3 deacetylates mitochondrial } \\
\text { ribossomes controlling their activity. }\end{array}$} & \multirow{5}{*}[85]{} \\
\hline & & SIRT $^{\mathrm{N} 87 \mathrm{~A}}$ expression & Unaltered mitochondrial protein synthesis & & \\
\hline & & ShSIRT3 & Increased mitochondrial protein synthesis & & \\
\hline & Liver mitochondria from $\mathrm{SIRT}^{---}$mice & SIRT3-/- & \multirow{2}{*}{ Higher translational activity of mitochondrial ribosomes } & & \\
\hline & Bovine liver mitochondria & Isolation with $10 \mathrm{mM}$ Nicotinamide & & & \\
\hline \multirow{2}{*}{ SIRT3 } & \multirow{2}{*}{$\mathrm{C} 2 \mathrm{C} 12$ myotubes } & SIRT3 overexpression & mtDNA copy number increased by 1.7 -fold & \multirow{2}{*}{$\begin{array}{l}\text { Proposes SIRT3 as a PGC-1 } 1 \alpha \text { downstream target gene } \\
\text { and a regulator of PGC- } 1 \alpha \text { effects on mitochondrial } \\
\text { metabolism. SIRT3 suggested to suppress ROS levels } \\
\text { and regulate mitochondrial biogenesis. }\end{array}$} & \multirow{2}{*}[84]{} \\
\hline & & ShSIRT3 & Unaltered mtDNA copy number & & \\
\hline Class I, Ila and IIb & \multirow{2}{*}{ SH-SY5Y neuroblastoma } & $0.4 \mu \mathrm{M}$ TSA (16-18h) & \multirow{2}{*}{ Increased PGC- $1 \alpha$ mRNA } & \multirow{2}{*}{$\begin{array}{l}\text { Reports that PGC- } 1 \alpha \text { overexpression protects SH-SY5Y } \\
\text { cells and that HDAC inhibition upregulates PGC- } 1 \alpha \text {. }\end{array}$} & \multirow{2}{*}[50]{} \\
\hline Class I and IIa & & $10 \mathrm{mM}$ Valproate (16-18h) & & & \\
\hline \multirow[t]{2}{*}{ HDAC5 } & $\begin{array}{l}\text { Mice with doxycycline (DOX)-inducible cardiac- } \\
\text { specific HDAC5S/A signal-resistant mutant }\end{array}$ & $\begin{array}{l}\text { (+) vs. (-) DOX: represses vs. induces } \\
\text { HDAC5S/A transcription }\end{array}$ & $\begin{array}{l}\text { (+) DOX decreased mitochondria number. (-)DOX decreased } \\
\text { PGC-1 } 1 \alpha \text { expression }\end{array}$ & \multirow{3}{*}{$\begin{array}{l}\text { Identifies HDAC5 as an indirect PGC- } 1 \alpha \text { transcription } \\
\text { regulator via MEF2 activity control. }\end{array}$} & \multirow{3}{*}[49]{} \\
\hline & \multirow{2}{*}{ COS cells } & HDAC5S/A expression & Prevents PGC- $1 \propto \alpha$ promoter activation by MEF2 & & \\
\hline HDAC3 & & HDAC3 overexpression & Does not alter PGC- $1 \alpha$ promoter activation by MEF2 & & \\
\hline
\end{tabular}


SIRT3 in myotubes decreased PGC- $1 \alpha$-mediated mitochondrial biogenesis, and authors proposed that SIRT3 might regulate NRF-1 and Tfam activities [84]. Interestingly, another study reported that SIRT3 deacetylates the ribosomal protein MRPL10 down-regulating the synthesis of mitochondrial proteins. Consistently, SIRT3 knockout mice presented increased expression of mitochondrially-encoded components of oxidative phosphorylation [85]. Thus, whether SIRT3 positively or negatively modulates mitochondrial biogenesis remains uncertain and, as far as we could find, unaddressed in neurons. Nevertheless, it was recently shown that expression of either SIRT3 or PGC- $1 \alpha$ was neuroprotective in an amyotrophic lateral sclerosis model, rescuing defects in mitochondrial dynamics [86], specifically fission-fusion dynamics, which is the subject of the next section.

\section{Fission-fusion}

Mitochondria are a highly dynamic organelle population that changes size and morphology by fusing together or dividing through fission. Mitochondrial fusion enables the exchange of mtDNA and other matrix components between mitochondria, rendering protection against mtDNA mutations by allowing functional complementation and thus maintaining a healthy oxidative phosphorylation system [87,88]. Mitochondrial fission permits mitochondrial separation to daughter cells during mitosis [89], allows segregation of dysfunctional mitochondria to be targeted for mitophagy [90], and enables the mitochondrial size and shape adaptations required for distribution in neuronal ramifications [91-93] (Fig. 1).

Mitochondrial fusion involves merging of the outer as well the inner mitochondrial membranes, a coordinated process assisted by different proteins [94]. Mitofusins (Mfn1 and Mfn2) promote outer membrane fusion. These are highly homologous GTPases anchored to the outer membrane and able to form homo- or hetero-protein complexes [95], which allows mitochondrial tethering and fusion in a GTP hydrolysis-dependent manner [96]. Inner membrane fusion depends on optic atrophy 1 (OPA1), a GTPase protein also involved in maintaining/ remodeling cristae structure [97]. OPA1 operates similarly to mitofusins, forming trans-complexes that lead to inner membrane fusion $[98,99]$. Mutations in Mfn2 cause Charcot-Marie-Tooth type 2A neuropathy [100], whereas mutations in OPA1 cause autosomal dominant optic atrophy [101].

Mitochondrial fission in mammals is mediated by Drp1, a cytosolic dynamin-related protein that is recruited to specific sites on the mitochondrial outer membrane and homo-oligomerizes, forming spiral chains around mitochondria that constrict and ultimately scission mitochondria in a GTP hydrolysis-dependent manner [102]. Significantly, a dominant-negative mutation in Drp1 was reported in a newborn with lethal neurodevelopmental abnormalities, exhibiting defects in both mitochondrial and peroxisomal fission [103]. Consistently, Drp1 knockout causes abnormal brain development and embryonic death in mice [92]. In yeast, Drp1 attaches to mitochondria by binding to Fis1, a protein anchored to the mitochondrial outer membrane. In mammals, however, other mitochondrial outer membrane proteins seem to take over the Drp1 receptor role. Thus, mitochondrial fission factor (Mff) was proposed as an essential factor for Drp1 recruitment, mediating fission independently from Fis1 [104]. Alternatively, mitochondrial elongation factor 1 (MIEF1) [105], also identified as MiD49/51 [106], can bind Drp1 and inhibit its GTP hydrolysis thus promoting fusion instead of fission [107]. According to such model, Fis1 could promote fission by sequestering MIEF1 and consequently unblocking Drp1 GTP hydrolysis [105,107]. It is also possible that MIEF1 levels determine the outcome, with elevated levels compromising selective Drp1 recruitment to constriction sites, leading to its uniform distribution, preventing formation of active scission complexes, and thus causing fusion instead of fission [106]. Recently, Fis1 was also proposed to modulate mitochondrial morphology by recruiting the GTPase regulator protein TBC1D15, in a Drp1-independent manner [108]. Thus, while both Drp1 and Fis1 seem to be key players in the regulation of mammalian mitochondrial dynamics, whether and how they interplay remains to be unraveled.

\subsection{KDACs and mitochondrial fission-fusion}

Treatment with different KDAC inhibitors, including pan-, class I- and isoform-selective inhibitors, induced mitochondrial elongation in several cell lines, including primary cultures, untransformed and cancer cell lines [109]. Mitochondrial elongation occurred at both subtoxic and toxic concentrations, indicating that mitochondrial structural integrity per se was not sufficient to protect cells against apoptotic stimuli. Further, the KDAC inhibitors increased histone $\mathrm{H} 3$ acetylation, decreased Fis1 expression levels, and decreased Drp1 recruitment to the mitochondria, without altering the levels or acetylation status of the Drp1, Mff, Mfn1, Mfn2, and OPA1 proteins [109]. These findings suggest that mitochondrial elongation by KDAC inhibitors resulted from the down-regulation of an essential mitochondrial fission mediator, Fis1, which was recently reported as a mitochondrial fusion preventer via MIEF1 sequestration [105] (Fig. 1).

The concept that KDAC inhibitors decrease Fis1 levels may, at first, seem unexpected given the general view that increased histone acetylation should promote transcription and, consequently, protein expression. Still, KDACs act on multiple non-histone targets, and changes in the lysine acetylation status of transcription factors may either increase or decrease their activity [4]. Also, KDAC inhibition has been shown to down-regulate proteins by promoting their ubiquitin-dependent degradation; e.g. DNA methyltransferase 1 (DNMT1) is polyubiquitinated when KDAC inhibition hyperacetylates the Hsp90 chaperone preventing its interaction with DNMT1 [110]. Thus, the reported decrease in Fis1 protein levels [109] might partly result from increased degradation, and not necessarily from decreased transcription.

Increased mitochondrial fragmentation was reported for human fibroblasts treated with nicotinamide [111]. Similar findings were reported for SIRT1 activators, SRT1720 or fisetin, only when SIRT1 expression was intact [112]. Nicotinamide, one of the final products of sirtuin-catalyzed deacetylation, is frequently used as a sirtuin inhibitor. However, it is reported to activate SIRT1 when used in lower concentrations $(5 \mathrm{mM})$, since nicotinamide readily converts into the SIRT1 cofactor $\mathrm{NAD}^{+}$via the "NAD ${ }^{+}$salvage pathway" [112]. Together with increased mitochondrial fragmentation, nicotinamide reduced the mitochondrial mass, increased mitochondrial membrane potential $\left(\Delta \psi_{\mathrm{m}}\right)$, and evoked a time-dependent increase in the levels of Drp1, Fis1 and Mfn1. Thus, it was suggested that nicotinamide enhances mitochondrial quality, with optimized levels of fission and fusion mediators facilitating separation of defective mitochondria for mitophagy [111], this being mediated by high $\mathrm{NAD}^{+}$:gNADH ratio and SIRT1 activation [112] (Fig. 1; Table 2).

\subsection{Neuronal mitochondrial fission-fusion and KDAC modulation}

In spite of accumulating evidence for abnormal mitochondrial fissionfusion dynamics in neurodegenerative diseases, there is limited data on the regulation of neuronal mitochondrial morphology by KDAC modulation. Impaired mitochondrial fusion and smaller mitochondrial size were recently reported for motor neurons expressing mutant superoxide dismutase (SOD1) [113]. Accordingly, previous studies reported decreased mitochondrial length and disrupted mitochondrial distribution in cell and animal models of amyotrophic lateral sclerosis (ALS) [114-116], which may stem from decreased OPA1 and increased Drp1 levels in mitochondria [117]. Concerning KDACs in this context, it was recently reported that SIRT3 overexpression rescued mitochondrial fragmentation in cortical neurons expressing SOD1 ${ }^{\text {G93A }}$ [86]. While the mechanisms by which SIRT3 corrects mitochondrial morphology remain uncertain, it was proposed that SIRT3 deacetylation of cyclophilin D and resulting inhibition of mitochondrial permeability transition may play a neuroprotective role [86]. 


\begin{tabular}{|c|c|c|c|c|c|}
\hline KDAC isoform & Model & Activity Modulation Method & Main Findings & Comments & Ref. \\
\hline \multirow{6}{*}{ SIRT1 } & \multirow{6}{*}{ Normal human fibroblasts } & $5 \mathrm{mM}$ Nicotinamide & $\begin{array}{l}\text { Mitochondrial fragmentation and decreased mitochondrial } \\
\text { content. }\end{array}$ & \multirow{6}{*}{$\begin{array}{l}\text { Reports that } 5 \mathrm{mM} \text { nicotinamide converts in } \mathrm{NAD}^{+} \\
\text {through the "NAD salvage pathway", increasing the } \\
\mathrm{NAD}+/ \mathrm{NADH} \text { ratio and activating SIRT1, which leads to } \\
\text { mitochondrial fragmentation and autophagy activation. }\end{array}$} & \multirow{6}{*}{ [112 } \\
\hline & & $20 \mathrm{mM}$ Nicotinamide & Increased mitochondrial content. & & \\
\hline & & $1 \mu \mathrm{M}-5 \mathrm{mM} \mathrm{NAD}+$ & Mitochondrial fragmentation and decreased mitochondrial & & \\
\hline & & \begin{tabular}{|l} 
Resveratrol \\
\end{tabular} & & & \\
\hline & & $10 \mu \mathrm{M}$ Fisetin + siSIRT1 & \multirow{2}{*}{$\begin{array}{l}\text { Mitochondrial fragmentation and decreased mitochondrial } \\
\text { content rescued by SIRT1 KO. }\end{array}$} & & \\
\hline & & 160 nM SRT1720 + siSIRT1 & & & \\
\hline SIRT1 & Mice with heart-specific SIRT1 overexpression & $\begin{array}{l}\text { Low, moderate, and high SIRT1 } \\
\text { expression }\end{array}$ & Unaltered mitochondrial size & $\begin{array}{l}\text { Reports that constitutive SIRT1 overexpression in the } \\
\text { heart impairs mitochondria and reduces cardiac } \\
\text { function. }\end{array}$ & [186] \\
\hline SIRT1 & Mouse POMC neurons & $1.5 \mathrm{nmol} /$ mouse EX-527 (i.c.v.) & $\begin{array}{l}\text { Unaltered mitochondrial morphology. Unaltered soma } \\
\text { mitochondria cross-sectional area and circularity. }\end{array}$ & $\begin{array}{l}\text { SIRT1 blocked recruitment of inhibitory synapses onto } \\
\text { POMC neurons, increasing their activity. Suggests that } \\
\text { SIRT1 activation in NPY/Agrp neurons is essential for } \\
\text { the physiological adaptations to negative energy } \\
\text { balance. }\end{array}$ & [69] \\
\hline SIRT1 & Normal human fibroblasts & $5 \mathrm{mM}$ Nicotinamide & $\begin{array}{l}\text { Induced mitochondrial fragmentation and reduced } \\
\text { mitochondrial mass. Increased Drp1, Fis1 and Mfn1 expression } \\
\text { levels. }\end{array}$ & $\begin{array}{l}\text { Proposes that nicotinamide optimises mitochondrial } \\
\text { quality control by promoting fragmentation and } \\
\text { mitophagy. }\end{array}$ & [111] \\
\hline SIRT2-3 & Spinal cord tissue from SOD ${ }^{\mathrm{G} 93 \mathrm{~A}}$ mice & $\begin{array}{l}\text { SIRT2 Fluorimetric Drug Discovery Kit } \\
\text { (Enzo Life Science) - buffer containing } \\
10 \mathrm{mM} \text { nicotinamide and } 1 \mu \mathrm{M} \text { TSA } \\
\end{array}$ & Decreased deacetylase activity & \multirow{2}{*}{$\begin{array}{l}\text { SOD1 }{ }^{\mathrm{G} 93 \mathrm{~A}} \text { mutation increases mitochondria } \\
\text { fragmentation and impairs movement. Non-functional } \\
\text { Drp1 decreases mitochondria fragmentation, restores } \\
\text { movement and diminishes cell death in SOD }{ }^{\mathrm{G} 3 \mathrm{~A}} \text { motor } \\
\text { neurons. SIRT3 or PGC- } 1 \alpha \text { transfection rescued } \\
\text { mitochondrial fragmentation improving neuronal } \\
\end{array}$} & \multirow{2}{*}{ [86] } \\
\hline SIRT3 & Mice cortical neurons expressing SOD1 ${ }^{\mathrm{G} 93 \mathrm{~A}}$ & SIRT3 overexpression & SIRT3 expression rescued mitochondrial fragmentation & & \\
\hline Class I, IIla and IIb & Hер3В (hepatoma cell line) & $\begin{array}{l}8 \mu \mathrm{M} \text { SAHA }(48 \mathrm{~h}) \text { - induces } 50 \% \text { cell } \\
\text { death }\end{array}$ & $\begin{array}{l}\text { Mitochondrial elongation. Decreased Fis1 expression and Drp1 } \\
\text { translocation to the mitochondria. Unaltered Drp1, Mff, Mfn1, } \\
\text { Mfn2 and OPA1 expression. Increased H2A, H3 and H4 } \\
\text { acetylation. Unaltered Drp1, Fis1, Mfn1 and OPA1 acetylation. }\end{array}$ & \multirow{4}{*}{$\begin{array}{l}\text { Reports that small molecule KDAC inhibition elongates } \\
\text { mitochondria even at concentrations causing 50\% cell } \\
\text { death. Decreased Fis1 expression might be involved. }\end{array}$} & \multirow{4}{*}{ [109] } \\
\hline \multirow{3}{*}{$\begin{array}{l}\text { Class I, Ila and IIb } \\
\text { (TSA). Class I and } \\
\text { IIa (VPA and } \\
\text { NaBut), Class I } \\
\text { (Trapoxin A), } \\
\text { HDAC2, } 3 \text { and } 8 \\
\text { (Apicidin A), } \\
\text { HDAC1 (MS-275) } \\
\end{array}$} & ARPE19 (retinal pigment epithelium cell line) & \multirow{3}{*}{$\begin{array}{l}40 \mu \mathrm{M} \text { TSA; } 30 \mathrm{mM} \text { VPA; } 10 \mathrm{mM} \\
\text { Sodium Butyrate; } 10 \mathrm{nM} \text { Trapoxin A; } 1 \\
\text { ug Apicidin A; } 15 \mu \mathrm{M} \text { MS-275 ( } 48 \mathrm{~h} \text { ) - } \\
\text { These concentrations induce apoptosis } \\
\text { in } \sim 50 \% \text { cells after } 48 \mathrm{~h}\end{array}$} & Mitochondrial elongation. Increased H3 acetylation. & & \\
\hline & Primary rat articular chondrocytes & & \multirow[b]{2}{*}{ Mitochondrial elongation } & & \\
\hline & $\begin{array}{l}\text { Cancer cell lines (Hep3B, T98G, U118MG, } \\
\text { U87MG, U373MG, PC3, ZR-75-1, and KAT18) }\end{array}$ & & & & \\
\hline Class I, IIa and IIb & \multirow{2}{*}{$\begin{array}{l}\text { DRG neurons from } 10 \text { months-old } \mathrm{HSPB}^{\mathrm{S} 135 \mathrm{~F}} \\
\text { mice }\end{array}$} & $0.4 \mu \mathrm{M}$ TSA (12h) & \multirow{2}{*}{ Increased mitochondria number } & \multirow{4}{*}{$\begin{array}{l}\text { Mutant HSPB1 mice presented impaired mitochondria } \\
\text { movement and decreased acetylated-tubulin in } \\
\text { peripheral nerves. HDAC6 inhibition reverted the } \\
\text { phenotype. }\end{array}$} & \multirow{4}{*}{ [158] } \\
\hline HDAC6 & & $2 \mu \mathrm{M}$ Tubacin or $1 \mu \mathrm{M}$ Tubastatin $\mathrm{A}(12 \mathrm{~h})$ & & & \\
\hline Class I, IIa and IIb & \multirow{2}{*}{$\begin{array}{l}\text { DRG neurons from } 8 \text { months-old } H S P B 1^{S 135 F} \\
\text { mice }\end{array}$} & $10 \mathrm{mg} / \mathrm{kg}$ TSA ( 3 weeks in vivo) & Unaltered mitochondria number & & \\
\hline HDAC6 & & $25 \mathrm{mg} / \mathrm{kg}$ Tubastatin A (3 weeks in vivo) & Increased mitochondria number & & \\
\hline HDAC6 & Rat primary hippocampal neurons & $5 \mu \mathrm{M}$ Tubastatin $\mathrm{A}(3 \mathrm{~h})$ & Unaltered mitochondria length or density & $\begin{array}{l}\text { Reports that HDAC6 inhibition increases } \alpha \text {-tubulin } \\
\text { acetylation, preventing axonal mitochondrial trafficking } \\
\text { impairment and disrupted morphology caused by } A_{1-42} \text {. }\end{array}$ & [157] \\
\hline Class I, Ila and IIb & \multirow{2}{*}{ SH-SY5Y neuroblastoma } & $0.4 \mu \mathrm{M}$ TSA (16-18h) & \multirow{2}{*}{ Unaltered Mfn1 and Mfn2 gene expression } & \multirow{2}{*}{$\begin{array}{l}\text { Reports that PGC- } 1 \alpha \text { overexpression protects SH-SY5Y } \\
\text { cells and that HDAC inhibition upregulates PGC-1 } \alpha .\end{array}$} & \multirow{2}{*}{ [50] } \\
\hline Class I and IIa & & $10 \mathrm{mM}$ Valproate (16-18h) & & & \\
\hline HDAC5 & $\begin{array}{l}\text { Mice with doxycycline (DOX)-inducible cardiac- } \\
\text { specific HDAC5S/A signal-resistant mutant }\end{array}$ & $\begin{array}{l}\text { (+)DOX - represses HDAC5S/A } \\
\text { transcription (-)DOX - induces } \\
\text { HDAC5S/A transcription }\end{array}$ & (-)DOX mitochondria were swollen with disrupted cristae & $\begin{array}{l}\text { Identifies HDAC5 as an indirect PGC-1a transcription } \\
\text { regulator via MEF2 activity control. }\end{array}$ & [49] \\
\hline
\end{tabular}




\subsection{Mitochondrial fission-fusion in neurodegeneration}

Abnormal mitochondrial fission-fusion dynamics, with disequilibrium towards fission has been described for multiple neurodegenerative disorders. In the AD brain, reductions in Mfn1, Mfn2, OPA1 and Drp1 levels were reported together with increased Fis1 levels [118]. In the context of PD, mutations in the serine/threonine kinase PINK1 or in the E3 ubiquitin ligase Parkin are major causes of familial PD, and these two proteins seem to functionally interact in the control of mitochondrial dynamics, albeit not in a simple linear pathway [119]. Mutant PINK1 is reported to promote mitochondrial fission or decrease fusion in mammalian cells. Possible mechanisms are that mutant PINK1 promotes Drp1 mitochondrial translocation, and interferes with wild-type PINK1 pro-fusion effect of increasing the fusion/fission protein ratio [120]. Parkin acts downstream of PINK1, thus mutations in either protein may promote fission by reducing wild-type Parkin-promoted degradation of Drp1 [121] or Fis1 [120].

HD is also associated with increased mitochondrial fission, with a study in patients' brain samples reporting increased expression of Drp1 and Fis1, and decreased expression of Mfn1, Mfn2, and OPA1 [122]. This contrasts with findings in several HD cell lines reporting no relevant changes in pro-fission or pro-fusion protein levels [123]. Alternatively, the pro-fission phenotype observed in HD cells may stem from abnormal $\mathrm{Ca}^{2+}$ homeostasis activating calcineurin, which dephosphorylates Drp1 promoting its translocation onto mitochondria [123-125]. Consistently, a recent study proposes that phosphorylation hinders Drp1 oligomerization, reducing its recruitment by Mff or preventing completion of fission-competent Drp1 spirals, thus inhibiting mitochondrial fission [126]. Alternatively, increased mitochondrial fission in HD may stem from an abnormal interaction between mutant huntingtin and Drp1, which is proposed to increase Drp1 enzymatic activity and thus promotes mitochondrial fragmentation [127,128]. Similarly, in AD context, beta amyloid was reported to abnormally interact with Drp1 [129].

The growing association of mitochondrial fission and neurodegeneration has sprouted the interest in compounds capable of inhibiting mitochondrial fission. Still, while inhibiting mitochondrial fission may afford protection against acute injury [130], it is becoming clearer that in the long run, inhibiting fission is not beneficial to neurons $[91,93,131]$. Thus, decreasing fission probability by epigenetic modulation, namely with KDAC inhibitors [109], is worth further examination as an alternative to direct fission inhibition.

\section{Movement}

Mitochondrial movement allows their efficient distribution throughout the cell. This is particularly relevant in the highly polarized neurons, where ATP diffusion per se would be inefficient, and thus mitochondria must travel to supply distant and metabolically demanding sites such as synapses, nodes of ranvier, and active growth cones [132]. In mammalian cells, mitochondrial transport relies heavily on microtubules, and motor and adaptor proteins. The kinesin-1 motor family (KIF5) drives anterograde transport assisted by adaptors such as Milton orthologues (TRAK1 and TRAK2) linked to mitochondrial rho (MIRO), an outer membrane RHO family GTPase and $\mathrm{Ca}^{2+}$ sensor. Syntabulin and FEZ1 are other KIF5-mitochondria adaptors, possibly allowing directed responses to different physiological signals [131]. The motor dynein typically drives retrograde mitochondrial movement, but may also be involved in bidirectional transport. Also, presence of both KIF5 and dynein in the same single mitochondrion allows for complex bidirectional movement, possibly coordinated by dynactin, which enhances dynein processivity $[131,133]$. A key element for microtubule-based docking of mitochondria in sites of need is syntaphilin, which acts as a 'static anchor' for axonal mitochondria thus regulating their mobility [134].

\subsection{Microtubule deacetylases and mitochondrial movement}

Microtubules are key cytoskeletal elements involved in neuronal mitochondrial trafficking. They are polymers of $\alpha / \beta$-tubulin heterodimers and their functional diversity can be regulated by PTMs $[135,136]$. Acetylation of $\alpha$-tubulin at lysine 40 was reported as a specific PTM that enhances recruitment of kinesin- 1 and dynein/dynactin motor complexes to microtubules, and stimulates anterograde and retrograde transport $[137,138]$. KATs such as the ARD1-NAT1 (ADP-ribosylation factor domain protein 1 in complex with $\mathrm{N}$-terminal acetyltransferase), and the Elongator complex, where shown capable of acetylating $\alpha$-tubulin $[136,139]$. Subsequently, $\alpha$ TAT1 was proposed as the major and possibly the sole $\alpha$-tubulin K40 acetyltransferase in mammals and nematodes [140]. Conversely, two KDACs, specifically HDAC6 and SIRT2, were found to interact and deacetylate $\alpha$-tubulin in vitro and in vivo [141-143] (Fig. 1; Table 3).

HDAC6 and SIRT2 were reported to co-localize along the microtubule network and coimmunoprecipitate. Also, silencing of HDAC6 or SIRT2 alone sufficed to evoke tubulin hyperacetylation [142]. Taken together with the report that tubulin does not bind HDAC6 or SIRT2 individually [144], these data supported the hypothesis that HDAC6 and SIRT2 act interdependently in a protein complex. There are other studies, however, suggesting they are unlikely binding partners in vivo given their different expression profiles in brain cells, with HDAC6 predominating in neurons (esp. Purkinje cells) and SIRT2 in oligodendrocytes $[26,145]$. Still, there is also evidence for SIRT2 expression in hippocampal, cortical and striatal neurons in vitro [146,147], and a study reporting abundant neuronal expression of SIRT2, particularly in the adult brain [27]. In such study, authors allude to a previous observation that tubulin is "not hyperacetylated" in the brains of HDAC6-deficient mice, and explain it with the possibility that abundant SIRT2 compensates for lack of HDAC6 [27]. Such allusion, however, contrasts with the original publication in HDAC6-deficient mice, where the respective authors state that no significant increase in tubulin acetylation was found because, in the brain, tubulin is "already highly acetylated" in wild-type animals, and therefore, HDAC6 inactivation has no visible impact on acetylation levels [148]. Still, a recent study reports significant increases in $\alpha$-tubulin K40 acetylation in HDAC6 $^{-/-}$ mice [149].

SIRT2-mediated modulation of mitochondrial trafficking has not been reported, as far as we could find in the literature. Nevertheless, there are reports that SIRT2 inhibition does modulate neuronal physiology, being neuroprotective in disease models highly associated with mitochondrial dysfunction, such as PD and HD. Specifically, SIRT2 inhibition protected against $\alpha$-synuclein toxicity, decreasing dopaminergic neuron death in both in vitro and in vivo (Drosophila) PD models, with the suggested mechanisms being that increased $\alpha$-tubulin acetylation promotes coalescence of misfolded proteins into larger protective inclusions [150]. SIRT2 inhibition was also found protective in a striatal neuron model of HD, by a mechanism involving decreased sterol biosynthesis [147]. Such mechanism has been questioned partly due to contrasting evidence that low sterol/cholesterol levels are associated with HD neurodegeneration [151]. Thus, further studies are required to elucidate the putative neuroprotective role of SIRT2 inhibition and its effects on mitochondrial dynamics.

HDAC6 inhibition promoted both retrograde and anterograde mitochondrial movement in hippocampal neurons, together with increased tubulin acetylation and KIF5-mitochondria association. Further, Glycogen Synthase Kinase 33 (GSK3 3 ) inhibition: reduced HDAC6 phosphorylation at serine 22; increased tubulin acetylation; and enhanced mitochondrial movement. Thus, leading to the proposal that GSK3 $\beta$ may regulate HDAC6 activity by phosphorylation [152]. The implications are that misregulation of HDAC6, presumably overactivated by GSK3 $\beta$-mediated phosphorylation, might underlie impaired mitochondrial transport. Significantly, mitochondrial and vesicular trafficking impairment in $A D$ models was associated with abnormal GSK3 $\beta$ activation [153,154]. 
Table 3

KDACs and mitochondrial movement or mitophagy.

\begin{tabular}{|c|c|c|c|c|c|}
\hline KDAC isoform & Model & Activity Modulation Method & Main Findings & Comments & Ref. \\
\hline HDAC6 & Rat primary hippocampal neurons & $5 \mu \mathrm{M}$ Tubastatin $\mathrm{A}(3 \mathrm{~h})$ & $\begin{array}{l}\text { Increased anterograde/retrograde mitochondrial velocity and } \\
\% \text { motility }\end{array}$ & $\begin{array}{l}\text { Reports that HDAC6 inhibition increases } \alpha \text {-tubulin } \\
\text { acetylation, preventing axonal mitochondrial trafficking } \\
\text { impairment and disrupted morphology caused by A } 1-42\end{array}$ & {$[157]$} \\
\hline Class I, IIa and IIb & \multirow{3}{*}{$\begin{array}{l}\text { DRG neurons from } 10 \text { months-old } \mathrm{HSPB}_{1} 1^{5135 \mathrm{~F}} \\
\text { mice }\end{array}$} & $0.4 \mu \mathrm{M}$ TSA (12h) & \multirow{5}{*}{ Increased number of motile mitochondria } & \multirow{5}{*}{$\begin{array}{l}\text { Mutant HSPB1 mice presented impaired mitochondria } \\
\text { movement and decreased acetylated-tubulin in } \\
\text { peripheral nerves. HDAC6 inhibition reverted the } \\
\text { phenotype. }\end{array}$} & \multirow{5}{*}{ [158] } \\
\hline \multirow{2}{*}{ HDAC6 } & & $2 \mu \mathrm{M}$ Tubacin $(12 \mathrm{~h})$ & & & \\
\hline & & $1 \mu \mathrm{M}$ Tubastatin $\mathrm{A}(12 \mathrm{~h})$ & & & \\
\hline Class I, IIa and IIb & \multirow{2}{*}{$\begin{array}{l}\text { DRG neurons from } 8 \text { months-old } \mathrm{HSPB}_{1} 1^{\mathrm{S135F}} \\
\text { mice }\end{array}$} & $10 \mathrm{mg} / \mathrm{kg}$ TSA ( 3 weeks in vivo) & & & \\
\hline HDAC6 & & $25 \mathrm{mg} / \mathrm{kg}$ Tubastatin A (3 weeks in vivo) & & & \\
\hline HDAC1 & \multirow[b]{2}{*}{ Rat primary cortical and hippocampal neurons } & MS-275 & $\begin{array}{l}\text { HDAC1 inhibition prevents mitochondrial trafficking } \\
\text { impairment caused by glutamate and TNF- } \alpha \text { treatment }\end{array}$ & \multirow{2}{*}{$\begin{array}{l}\text { Reports that, in neurons exposed to excitotoxic or } \\
\text { inflammatory injury, HDAC1 exits the nucleus and binds } \\
\text { motor proteins impairing mitochondrial trafficking. }\end{array}$} & \multirow[b]{2}{*}[159]{} \\
\hline HDAC6 & & Tubacin & $\begin{array}{l}\text { HDAC6 inhibition does not prevent mitochondrial trafficking } \\
\text { impairment caused by glutamate and TNF- } \alpha \text { treatment }\end{array}$ & & \\
\hline Class I, IIa and IIb & \multirow[b]{2}{*}{ Rat primary hippocampal neurons } & $10 \mu \mathrm{M}$ TSA (2h) & \multirow[b]{2}{*}{ Increased axonal mitochondria motility and velocity. } & \multirow{2}{*}{$\begin{array}{l}\text { This study shows that HDAC6 inhibition increases } \\
\text { axonal mitochondria trafficking and reports HDAC6 } \\
\text { activity is modulated by GSK3ß. HDAC6 inhibition } \\
\text { increased motor proteins recruitment to the } \\
\text { mitochondria. }\end{array}$} & \multirow[b]{2}{*}{ [152] } \\
\hline HDAC6 & & $20 \mu \mathrm{M}$ Tubacin $(2 \mathrm{~h})$ & & & \\
\hline \multirow{2}{*}{ HDAC6 } & $\begin{array}{l}\text { Primary hippocampal neurons from } \mathrm{HDAC6}^{-{ }^{--}} \\
\text {mice }\end{array}$ & \multirow{2}{*}{ HDAC6 KO } & $\begin{array}{l}\text { Prevented abnormal mitochondrial trafficking induced by } A \beta- \\
\text { derived diffusible ligands }\end{array}$ & \multirow{2}{*}{$\begin{array}{l}\text { Reports that reducing HDAC6 endogenous levels } \\
\text { improves memory function in AD mice, and suggests } \\
\text { that this may stem from improved mitochondrial } \\
\text { trafficking }\end{array}$} & \multirow{2}{*}{ [149] } \\
\hline & Hippocampi from APPPS1-21_HDAC6 ${ }^{-1-}$ mice & & Promoted neuronal mitochondrial distribution & & \\
\hline \multirow{3}{*}{ SIRT1 } & \multirow{3}{*}{ Mice with heart-specific SIRT1 overexpression } & Low SIRT1 expression & $\begin{array}{l}\text { Unaltered degenerated or collapsed mitochondria number. } \\
\text { Unaltered LC3b gene expression and LC3-II/LC3-I ratio. }\end{array}$ & \multirow{3}{*}{$\begin{array}{l}\text { Reports that constitutive SIRT1 overexpression in the } \\
\text { heart impairs mitochondria and reduces cardiac } \\
\text { function. }\end{array}$} & \multirow{3}{*}{ [186] } \\
\hline & & Moderate SIRT1 expression & $\begin{array}{l}\text { Increased ( } 2 x) \text { degenerated or collapsed mitochondria number. } \\
\text { Decreased LC3b gene expression and LC3-II/LC3-I ratio. }\end{array}$ & & \\
\hline & & High SIRT1 expression & $\begin{array}{l}\text { Increased (4x) degenerated or collapsed mitochondria number. } \\
\text { Decreased LC3b gene expression and LC3-II/LC3-I ratio. }\end{array}$ & & \\
\hline SIRT1 & Normal human fibroblasts & $5 \mathrm{mM}$ Nicotinamide & $\begin{array}{l}\text { Induced mitochondrial fragmentation and reduced mass. } \\
\text { Increased LC3 puncta and LC3-II/I ratio. Decreased Complex V } \\
\text { levels. }\end{array}$ & $\begin{array}{l}\text { Proposes that nicotinamide optimises mitochondrial } \\
\text { quality control by promoting fragmentation and } \\
\text { mitophagy. }\end{array}$ & {$[111]$} \\
\hline \multirow[t]{2}{*}{ HDAC6 } & \multirow{2}{*}{$\begin{array}{l}\text { Parkin-overexpressing mouse fibroblasts } \\
\text { treated with CCCP for } 16 \mathrm{~h} \text { to induce mitophagy }\end{array}$} & HDAC6 KO & Impaired mitophagy & \multirow{2}{*}{$\begin{array}{l}\text { Proposes that the ubiquitin-binding HDAC6 assists } \\
\text { mitophagy, being recruited to mitochondria } \\
\text { ubiquitinated by Parkin. HDAC6 was also reported to } \\
\text { deacetylate cortactin promoting F-actin remodelling } \\
\text { and autophagosome-lysosome fusion [170]. }\end{array}$} & \multirow{2}{*}{ [167] } \\
\hline & & $\begin{array}{l}\text { HDAC6 KO followed by reintroduction of } \\
\text { human HDAC6 }\end{array}$ & Restored mitophagy & & \\
\hline
\end{tabular}


Taken together, these data suggest that HDAC6 might be involved in linking GSK3 3 to the trafficking impairment in AD. In fact, evidence suggests that HDAC6 is involved in trafficking abnormalities in several neurodegenerative disorders, as addressed below.

\subsection{KDAC modulation of trafficking and neurodegeneration}

In neurodegenerative diseases such as Huntington and Alzheimer's, current evidence suggest a beneficial role for HDAC6 inhibition. Indeed, HD patients' brain samples exhibit decreased tubulin acetylation; and cellular HD models present compromised microtubule-dependent transport, suggesting that transport might be restored by tubulin deacetylase inhibition [138]. Consistently, selective HDAC6 inhibition with tubacin, but not HDAC1 inhibition with MS275, increased $\alpha$-tubulin acetylation at lysine 40; thus enhancing KIF5 and dynein recruitment to microtubules, and promoting bidirectional transport in striatal cell lines. Further, KDAC inhibitors capable of inhibiting HDAC6 were shown to enhance transport-dependent BDNF release in cortical neurons expressing either wild type or mutant N-terminal huntingtin constructs [138]. Similarly, decreased $\alpha$-tubulin acetylation [155] and increased HDAC6 levels [156] were reported for the AD brain, suggesting a role in abnormal mitochondrial trafficking in this disease. Also, in hippocampal neurons challenged with amyloid- $\beta$, HDAC6 inhibition with tubastatin A enhanced bidirectional mitochondrial motility, rescuing transport and reducing mitochondrial fragmentation [157]. More recently, HDAC6 deletion was reported to improve memory function in AD mice without affecting amyloid- $\beta$ plaque load [149]. Significantly, HDAC6 deletion protected primary neurons from mitochondrial trafficking defects induced by amyloid- $\beta$ derived diffusible ligands, and enhanced mitochondrial distribution in the hippocampi of AD mice [149].

Degeneration of the peripheral nervous system may also benefit from HDAC6 inhibition, as shown for Charcot-Marie-Tooth disease models with altered mitochondrial transport. In this context, mice expressing mutant heat-shock protein HSPB1 presented decreased acetylated tubulin and severe axonal transport deficits. Significantly, DRG neurons from symptomatic HSPB1 ${ }^{\mathrm{S} 135 \mathrm{~F}}$ mice exhibited decreased mitochondrial number and motility in their neurites. Pharmacological HDAC6 inhibition in vitro and in vivo rescued the mitochondrial number and motility phenotype in DRG neurons. Further, in vivo HDAC6 inhibition improved motor performance, together with improved electrophysiological/histological parameters, suggesting that it might be a useful therapeutic approach in peripheral neuropathies [158].

In spite of the above evidence, HDAC6 inhibition is unlikely a universal solution for abnormal axonal transport. Interestingly, evidence from neuroinflammation models points towards another HDAC - the normally nuclear-located HDAC1 - as playing a critical role in the onset of axonal damage and mitochondrial transport abnormalities, not ameliorated by HDAC6 inhibition. Neuroinflammatory stimuli (glutamate plus TNF $\alpha$ ) were reported to evoke a $\mathrm{Ca}^{2+}$-dependent nuclear export of HDAC1 [159]. Interestingly, pan-classical-KDAC inhibition improved neuronal $\mathrm{Ca}^{2+}$ recovery following glutamate receptor (NMDAR) activation [160]. $\mathrm{Ca}^{2+}$-dependent nuclear export appears to confer a cytosolic gain of function to HDAC1, namely, binding $\alpha$-tubulin and motor proteins (KIF5 and KIF2A), thus impairing their ability to transport cargo such as mitochondria, leading to localized neurite swelling and degeneration [159]. These toxic effects were partly rescued by preventing HDAC1 nuclear export, or by pharmacological inhibition of HDAC1 with MS275, but not by HDAC6 inhibition with tubacin [159]. Hence, it seems that different KDACs may impair mitochondrial transport as a function of different pathological triggers, explaining the opposite findings of inhibiting HDAC6 vs. HDAC1 in models of HD [138] vs. neuroinflammation [159] (Fig. 1). Still, inhibiting KDACs for rescuing mitochondrial transport must be balanced against putative interference with other roles, such as the role of HDAC6 in mitophagy.

\section{Mitophagy}

The selective degradation of defective mitochondria prevents them from releasing oxidants and apoptosis triggers, thus being critical for neuronal health and survival. The mitophagy machinery engulfs and digests small fusion-deficient mitochondria exhibiting sustained depolarization [161]. A key mitophagy regulator is the PINK1-Parkin signaling pathway. PINK1 acts as $\Delta \psi_{\mathrm{m}}$ sensor, recruiting Parkin to depolarized mitochondria, thus triggering the mitophagy machinery. Mechanistically, PINK1 is normally imported into polarized mitochondria and constitutively degraded by PARL (presenilin-associated rhomboid-like protein). In bioenergetic incompetent mitochondria, however, PINK1 is no longer degraded and accumulates in the outer membrane where it can recruit Parkin [162]. Through its E3 ubiquitin ligase activity, Parkin ubiquitinates mitochondrial proteins like VDAC1 [163] and MIRO (via an interplay with Pink1 that arrests damaged mitochondria [164,165]), and also ubiquitinates fusion mediators like mitofusins [166]. Thus, depolarized mitochondria are rendered fusion-deficient and with a coating that attracts the ubiquitin-binding autophagic components, p62 and HDAC6 [167-169] (Fig. 1).

\subsection{KDACs and mitophagy}

HDAC6 is reported to play a key role in the quality control autophagy of protein aggregates and mitochondria [167,170]. HDAC6 has the capacity to bind polyubiquitinated proteins and also dynein motors, thus linking target recognition with its transport to aggresomes [171,172]. Moreover, HDAC6 facilitates aggresome clearance [173,174] by controlling autophagosome-lysosome fusion [170] (Fig. 1; Table 3).

The HDAC6 ubiquitin- and dynein-binding motifs are distinct from the tubulin deacetylase domain that is selectively targeted by HDAC6 inhibitors [175], which were neuroprotective in several disease models $[138,157,158]$. Nevertheless, there is evidence that a functional HDAC6 deacetylase domain is required for aggresome formation, autophagosome-lysosome fusion and autophagic turnover [170,172-174]. Thus, although HDAC6 inhibition enhances mitochondrial and vesicle trafficking, it may hinder mitophagy as well as the turnover of misfolded proteins. Still, when reduced axonal trafficking is the main problem for a given disease state, HDAC6 inhibition might be beneficial if compensatory mechanisms allow for adequate protein and mitochondria turnover.

SIRT1 may partly compensate for HDAC6 inhibition. Autophagosomelysosome fusion requires cytosolic HDAC6 catalytic activity to deacetylate cortactin, which mediates the necessary F-actin remodeling [170]. Meaningfully, in the adult brain, SIRT1 is predominantly located in the cytosol [22], thus being in a position to interact with cortactin. In fact, HDAC6 and SIRT1 were both shown to bind and deacetylate cortactin independently, but may also work cooperatively or competitively, with their relative dominance being cell type dependent [176] (Fig. 1). Further, although HDAC6 knockout mice are reported to develop ubiquitin-positive brain aggregates [170], they are also described as developing normally, being fertile and viable, without obvious brain and spinal cord abnormalities [148]. Thus, it is conceivable that increased activity of SIRT1 might compensate for the consequences of HDAC6 knockout/inhibition on cortactin acetylation, and consequently on autophagosome-lysosome fusion.

SIRT1 activation was associated with mitophagy induction in human fibroblasts. Indeed, treatment with SIRT1 activators or with nicotinamide $\left(5 \mathrm{mM}-\mathrm{a}\right.$ concentration that converts to $\mathrm{NAD}^{+}$and activates SIRT1 [112]) was reported to accelerate mitophagy at least in part by inducing mitochondrial fragmentation. Consistently with quality control mitophagy activation, treated cells exhibited a decreased mitochondrial mass but increased $\Delta \psi_{\mathrm{m}}$; together with increased levels of the autophagosomal marker LC3-II, and higher number of mitochondriaassociated LC3 puncta and lysosomes [111,112; but see 186]. While the exact mechanisms downstream of SIRT1 activation remain uncertain, findings are consistent with the ongoing degradation of small 
depolarized mitochondria, which are preferential targets for mitophagy [161].

Further studies are required to clarify the interplay between HDAC6 and SIRT1 in the regulation of mitophagy. While HDAC6 modulation may have therapeutic potential in neurodegeneration [177], the effects of HDAC6 inhibition on axonal trafficking must be balanced against the fact that misfolded protein aggregates are a hallmark of several neurodegenerative diseases [178]. Therefore, HDAC6 inhibition aimed at promoting neuronal mitochondrial trafficking should be further explored to test for implications in autophagolysosome formation and clearance in neurons.

\subsection{Mitophagy in neurodegeneration}

Parkinson's disease has taken the lead in the research on mitophagy impairment, partly due to the links between the PINK1-Parkin pathway and familial forms of this neurodegenerative disorder [179]. Wild-type Parkin is selectively recruited to dysfunctional mitochondria and promotes their autophagy [180]. Parkin recruitment depends on functional PINK1, and loss of function mutations in PINK1 or Parkin can block mitophagy [163]. Thus, PD neurodegeneration may at least partly stem from impairment in selective mitochondrial clearance, leading to the accumulation of dysfunctional organelles.

In Alzheimer's disease brains, the area of intact mitochondria was found decreased in vulnerable neurons, together with increased mtDNA and proteins in vacuoles associated with lipofuscin. This increase in mitochondrial degradation products suggested either increased mitophagy or decreased proteolytic turnover [76]. Indeed, it has been proposed that $\mathrm{AD}$ mitochondria are susceptible to increased autophagic degradation [181,182], but it is still uncertain whether increased mitophagy is a protective response or contributing to pathology, possibly in a synergistic manner with dysfunctional fission-fusion dynamics [183]. Interestingly, increased Parkin expression in AD mice was shown to decrease intracellular amyloid- $\beta$ levels and extracellular plaque deposition, while also promoting autophagic clearance of defective mitochondria [184].

Huntington's disease cellular models were reported to exhibit defects in cargo recognition by autophagic vacuoles, preferentially affecting organelle sequestration, and leading to the accumulation of abnormal mitochondria. Further, an abnormal interaction between mutant huntingtin and the autophagic adaptor p62 was proposed to cause the cargo recognition failure [185]. Interestingly, it has been reported that HDAC6 is required for efficient autophagic degradation of aggregated huntingtin [173]. Thus, the modulation of HDAC6 activity might be an interesting strategy to improve the clearance of both mutant huntingtin and abnormal mitochondria in HD.

\section{Concluding remarks}

Lysine deacetylases are emerging therapeutic targets in neurodegeneration. Current evidence suggests that their modulation, namely with epigenetic drugs such as KDAC inhibitors, may assist correction of abnormal mitochondrial dynamics in neurodegenerative diseases. The enhancement of mitochondrial biogenesis, movement, quality control mitophagy, and the restoration of fission-fusion balance have all been proposed as neuroprotective strategies. Concerning mitochondrial biogenesis, it is predominantly reported enhanced by SIRT1 activation. Still, recent findings suggest caution in interpreting data generated with uncertain SIRT1 activators. Future studies should help clarify the SIRT1biogenesis connection and provide further mechanistic data for the role of SIRT3 and other KDACs in this process. Excessive mitochondrial fission is consistently reported for multiple neurodegenerative diseases, but arresting this crucial physiological event is also detrimental to neurons. Thus, decreasing fission probability with KDAC inhibitors is worth further examination as an alternative to direct fission inhibition. Abnormal mitochondrial transport has been associated with both HDAC6 and HDAC1 activities depending on the pathological trigger. In different neurodegenerative disease models, HDAC6 inhibition was shown to rescue trafficking abnormalities. Still, given the ubiquitin-binding and autophagosome-lysosome fusion promoting activities of HDAC6, the consequences of HDAC6 inhibition upon autophagy and clearance of misfolded proteins require further exploration. Conceivably, when reduced axonal trafficking is the main problem for a given disease state, HDAC6 inhibition might be beneficial if compensatory mechanisms allow for adequate autophagy and protein turnover.

\section{Acknowledgements}

This work is supported by Fundação para a Ciência e a Tecnologia via the Strategic Project PEst-C/EQB/LA006/2011, the Research Grant PTDC/ NEU-NMC/0237/2012 and COMPETE FCOMP-01-0124-FEDER-029649 to J.M.A. Oliveira, and by the PhD Grant SFRH/BD/72071/2010 to P. Guedes-Dias. We apologize to all authors not cited due to space limitations.

\section{References}

[1] X.J. Yang, E. Seto, Lysine acetylation: codified crosstalk with other posttranslational modifications, Mol. Cell 31 (2008) 449-461.

[2] C. Choudhary, C. Kumar, F. Gnad, M.L. Nielsen, M. Rehman, T.C. Walther, J.V. Olsen, M. Mann, Lysine acetylation targets protein complexes and co-regulates major cellular functions, Science 325 (2009) 834-840.

[3] M.A. Glozak, N. Sengupta, X. Zhang, E. Seto, Acetylation and deacetylation of non-histone proteins, Gene 363 (2005) 15-23.

[4] T. Kouzarides, Acetylation: a regulatory modification to rival phosphorylation? EMBO J. 19 (2000) 1176-1179.

[5] M.D. Shahbazian, M. Grunstein, Functions of site-specific histone acetylation and deacetylation, Annu. Rev. Biochem. 76 (2007) 75-100.

[6] X. Zhang, Z. Yuan, Y. Zhang, S. Yong, A. Salas-Burgos, J. Koomen, N. Olashaw, J.T. Parsons, X.J. Yang, S.R. Dent, T.P. Yao, W.S. Lane, E. Seto, HDAC6 modulates cell motility by altering the acetylation level of cortactin, Mol. Cell 27 (2007) 197-213.

[7] W. He, J.C. Newman, M.Z. Wang, L. Ho, E. Verdin, Mitochondrial sirtuins: regulators of protein acylation and metabolism, Trends Endocrinol. Metab. 23 (2012) 467-476.

[8] M. Haberland, R.L. Montgomery, E.N. Olson, The many roles of histone deacetylases in development and physiology: implications for disease and therapy, Nat. Rev. Genet. 10 (2009) 32-42.

[9] A.G. Kazantsev, L.M. Thompson, Therapeutic application of histone deacetylase inhibitors for central nervous system disorders, Nat. Rev. Drug Discov. 7 (2008) 854-868.

[10] O. True, P. Matthias, Interplay between histone deacetylases and autophagy - from cancer therapy to neurodegeneration, Immunol. Cell Biol. 90 (2012) 78-84.

[11] E.A. Schon, S. Przedborski, Mitochondria: the next (neurode)generation, Neuron 70 (2011) 1033-1053.

[12] X.J. Yang, E. Seto, The Rpd3/Hda1 family of lysine deacetylases: from bacteria and yeast to mice and men, Nat. Rev. Mol. Cell Biol. 9 (2008) 206-218.

[13] D. Waltregny, W. Glenisson, S.L. Tran, B.J. North, E. Verdin, A. Colige, V. Castronovo, Histone deacetylase HDAC8 associates with smooth muscle alpha-actin and is essential for smooth muscle cell contractility, FASEB J. 19 (2005) 966-968.

[14] N. Sengupta, E. Seto, Regulation of histone deacetylase activities, J. Cell. Biochem. 93 (2004) 57-67.

[15] X.J. Yang, E. Seto, Collaborative spirit of histone deacetylases in regulating chromatin structure and gene expression, Curr. Opin. Genet. Dev. 13 (2003) 143-153.

[16] W. Fischle, F. Dequiedt, M.J. Hendzel, M.G. Guenther, M.A. Lazar, W. Voelter, E. Verdin, Enzymatic activity associated with class II HDACs is dependent on a multiprotein complex containing HDAC3 and SMRT/N-CoR, Mol. Cell 9 (2002) 45-57.

[17] Y. Liu, L. Peng, E. Seto, S. Huang, Y. Qiu, Modulation of histone deacetylase 6 (HDAC6) nuclear import and tubulin deacetylase activity through acetylation, J. Biol. Chem. 287 (2012) 29168-29174.

18] J.J. Tong, J. Liu, N.R. Bertos, X.J. Yang, Identification of HDAC10, a novel class II human histone deacetylase containing a leucine-rich domain, Nucleic Acids Res. 30 (2002) 1114-1123.

[19] A. Villagra, F. Cheng, H.W. Wang, I. Suarez, M. Glozak, M. Maurin, D. Nguyen, K.L. Wright, P.W. Atadja, K. Bhalla, J. Pinilla-Ibarz, E. Seto, E.M. Sotomayor, The histone deacetylase HDAC11 regulates the expression of interleukin 10 and immune tolerance, Nat. Immunol. 10 (2009) 92-100.

[20] M. Lawson, U. Uciechowska, J. Schemies, T. Rumpf, M. Jung, W. Sippl, Inhibitors to understand molecular mechanisms of $\mathrm{NAD}(+)$-dependent deacetylases (sirtuins), Biochim. Biophys. Acta 1799 (2010) 726-739.

[21] S. Nemoto, M.M. Fergusson, T. Finkel, SIRT1 functionally interacts with the metabolic regulator and transcriptional coactivator PGC-1\{alpha\}, J. Biol. Chem. 280 (2005) $16456-16460$.

[22] Y. Li, W. Xu, M.W. McBurney, V.D. Longo, SirT1 inhibition reduces IGF-I/IRS-2/Ras/ERK1/2 signaling and protects neurons, Cell Metab. 8 (2008) $38-48$.

[23] R.M. Cowell, K.R. Blake, J.W. Russell, Localization of the transcriptional coactivator PGC-1alpha to GABAergic neurons during maturation of the rat brain, J. Comp. Neurol. 502 (2007) 1-18. 
[24] J.P. Little, A. Safdar, N. Cermak, M.A. Tarnopolsky, M.J. Gibala, Acute endurance exercise increases the nuclear abundance of PGC-1alpha in trained human skeletal muscle, Am. J. Physiol. Regul. Integr. Comp. Physiol. 298 (2010) R912-R917.

[25] A. Vaquero, M.B. Scher, D.H. Lee, A. Sutton, H.L. Cheng, F.W. Alt, L. Serrano, R. Sternglanz, D. Reinberg, SirT2 is a histone deacetylase with preference for histone H4 Lys 16 during mitosis, Genes Dev. 20 (2006) 1256-1261.

[26] C.M. Southwood, M. Peppi, S. Dryden, M.A. Tainsky, A. Gow, Microtubule deacetylases, SirT2 and HDAC6, in the nervous system, Neurochem. Res. 32 (2007) 187-195.

[27] M.M. Maxwell, E.M. Tomkinson, J. Nobles, J.W. Wizeman, A.M. Amore, L. Quinti, V. Chopra, S.M. Hersch, A.G. Kazantsev, The Sirtuin 2 microtubule deacetylase is an abundant neuronal protein that accumulates in the aging CNS, Hum. Mol. Genet. 20 (2011) 3986-3996.

[28] A. Bobrowska, G. Donmez, A. Weiss, L. Guarente, G. Bates, SIRT2 ablation has no effect on tubulin acetylation in brain, cholesterol biosynthesis or the progression of Huntington's disease phenotypes in vivo, PLoS One 7 (2012) e34805.

[29] K.M. Rothgiesser, S. Erener, S. Waibel, B. Luscher, M.O. Hottiger, SIRT2 regulates NF-kappaB dependent gene expression through deacetylation of p65 Lys310, J. Cell Sci. 123 (2010) 4251-4258.

[30] G. Jia, L. Su, S. Singhal, X. Liu, Emerging roles of SIRT6 on telomere maintenance, DNA repair, metabolism and mammalian aging, Mol. Cell. Biochem. 364 (2012) 345-350.

[31] M.F. Barber, E. Michishita-Kioi, Y. Xi, L. Tasselli, M. Kioi, Z. Moqtaderi, R.I. Tennen, S. Paredes, N.L. Young, K. Chen, K. Struhl, B.A. Garcia, O. Gozani, W. Li, K.F. Chua, SIRT7 links H3K18 deacetylation to maintenance of oncogenic transformation, Nature 487 (2012) 114-118.

[32] E. Ford, R. Voit, G. Liszt, C. Magin, I. Grummt, L. Guarente, Mammalian Sir2 homo$\log$ SIRT7 is an activator of RNA polymerase I transcription, Genes Dev. 20 (2006) 1075-1080.

[33] Y. Qiu, Y. Zhao, M. Becker, S. John, B.S. Parekh, S. Huang, A. Hendarwanto, E.D. Martinez, Y. Chen, H. Lu, N.L. Adkins, D.A. Stavreva, M. Wiench, P.T. Georgel, R.L. Schiltz, G.L. Hager, HDAC1 acetylation is linked to progressive modulation of steroid receptor-induced gene transcription, Mol. Cell 22 (2006) 669-679.

[34] Y. Han, Y.H. Jin, Y.J. Kim, B.Y. Kang, H.J. Choi, D.W. Kim, C.Y. Yeo, K.Y. Lee, Acetylation of Sirt2 by p300 attenuates its deacetylase activity, Biochem. Biophys. Res. Commun. 375 (2008) 576-580.

[35] J.Y. Huang, M.D. Hirschey, T. Shimazu, L. Ho, E. Verdin, Mitochondrial sirtuins, Biochim. Biophys. Acta 1804 (2010) 1645-1651.

[36] M. Pacholec, J.E. Bleasdale, B. Chrunyk, D. Cunningham, D. Flynn, R.S. Garofalo, D. Griffith, M. Griffor, P. Loulakis, B. Pabst, X. Qiu, B. Stockman, V. Thanabal, A. Varghese, J. Ward, J. Withka, K. Ahn, SRT1720, SRT2183, SRT1460, and resveratrol are not direct activators of SIRT1, J. Biol. Chem. 285 (2010) 8340-8351.

[37] B.P. Hubbard, A.P. Gomes, H. Dai, J. Li, A.W. Case, T. Considine, T.V. Riera, J.E. Lee, S.Y.E, D.W. Lamming, B.L. Pentelute, E.R. Schuman, L.A. Stevens, A.J. Ling, S.M. Armour, S. Michan, H. Zhao, Y. Jiang, S.M. Sweitzer, C.A. Blum, J.S. Disch, P.Y. Ng, K.T. Howitz, A.P. Rolo, Y. Hamuro, J. Moss, R.B. Perni, J.L. Ellis, G.P. Vlasuk, D.A. Sinclair, Evidence for a common mechanism of SIRT1 regulation by allosteric activators, Science 339 (2013) 1216-1219.

[38] A.V. Bieliauskas, M.K. Pflum, Isoform-selective histone deacetylase inhibitors, Chem. Soc. Rev. 37 (2008) 1402-1413.

[39] C.M. Marson, Histone deacetylase inhibitors: design, structure-activity relationships and therapeutic implications for cancer, Anticancer Agents Med. Chem. 9 (2009) 661-692.

[40] P. Bertrand, Inside HDAC with HDAC inhibitors, Eur. J. Med. Chem. 45 (2010) 2095-2116.

[41] N. Khan, M. Jeffers, S. Kumar, C. Hackett, F. Boldog, N. Khramtsov, X. Qian, E. Mills, S.C. Berghs, N. Carey, P.W. Finn, L.S. Collins, A. Tumber, J.W. Ritchie, P.B. Jensen, H.S. Lichenstein, M. Sehested, Determination of the class and isoform selectivity of small-molecule histone deacetylase inhibitors, Biochem. J. 409 (2008) 581-589.

[42] K.V. Butler, J. Kalin, C. Brochier, G. Vistoli, B. Langley, A.P. Kozikowski, Rational design and simple chemistry yield a superior, neuroprotective HDAC6 inhibitor, tubastatin A, J. Am. Chem. Soc. 132 (2010) 10842-10846.

[43] M.B. Hock, A. Kralli, Transcriptional control of mitochondrial biogenesis and function, Annu. Rev. Physiol. 71 (2009) 177-203.

[44] I.G. Onyango, J. Lu, M. Rodova, E. Lezi, A.B. Crafter, R.H. Swerdlow, Regulation of neuron mitochondrial biogenesis and relevance to brain health, Biochim. Biophys. Acta 1802 (2010) 228-234.

[45] B.N. Finck, D.P. Kelly, PGC-1 coactivators: inducible regulators of energy metabolism in health and disease, J. Clin. Invest. 116 (2006) 615-622.

[46] Z. Wu, P. Puigserver, U. Andersson, C. Zhang, G. Adelmant, V. Mootha, A. Troy, S. Cinti, B. Lowell, R.C. Scarpulla, B.M. Spiegelman, Mechanisms controlling mitochondrial biogenesis and respiration through the thermogenic coactivator PGC-1, Cell 98 (1999) 115-124.

[47] F. Devaux, G. Lelandais, M. Garcia, S. Goussard, C. Jacq, Posttranscriptional control of mitochondrial biogenesis: spatio-temporal regulation of the protein import process, FEBS Lett. 584 (2010) 4273-4279.

[48] D. Kang, N. Hamasaki, Mitochondrial transcription factor A in the maintenance of mitochondrial DNA: overview of its multiple roles, Ann. N. Y. Acad. Sci. 1042 (2005) 101-108.

[49] M.P. Czubryt, J. McAnally, G.I. Fishman, E.N. Olson, Regulation of peroxisome proliferator-activated receptor gamma coactivator 1 alpha (PGC-1 alpha) and mitochondrial function by MEF2 and HDAC5, Proc. Natl. Acad. Sci. U. S. A. 100 (2003) 1711-1716.

[50] R.M. Cowell, P. Talati, K.R. Blake, J.H. Meador-Woodruff, J.W. Russell, Identification of novel targets for PGC-1alpha and histone deacetylase inhibitors in neuroblastoma cells, Biochem. Biophys. Res. Commun. 379 (2009) 578-582.
[51] C. Lerin, J.T. Rodgers, D.E. Kalume, S.H. Kim, A. Pandey, P. Puigserver, GCN5 acetyltransferase complex controls glucose metabolism through transcriptional repression of PGC-1alpha, Cell Metab. 3 (2006) 429-438.

[52] C. Canto, Z. Gerhart-Hines, J.N. Feige, M. Lagouge, L. Noriega, J.C. Milne, P.J. Elliott, P. Puigserver, J. Auwerx, AMPK regulates energy expenditure by modulating NAD + metabolism and SIRT1 activity, Nature 458 (2009) 1056-1060.

[53] S. Jager, C. Handschin, J. St-Pierre, B.M. Spiegelman, AMP-activated protein kinase (AMPK) action in skeletal muscle via direct phosphorylation of PGC-1alpha, Proc. Natl. Acad. Sci. U. S. A. 104 (2007) 12017-12022.

[54] C. Handschin, J. Rhee, J. Lin, P.T. Tarr, B.M. Spiegelman, An autoregulatory loop controls peroxisome proliferator-activated receptor gamma coactivator 1alpha expression in muscle, Proc. Natl. Acad. Sci. U. S. A. 100 (2003) 7111-7116.

[55] H.Y. Cohen, C. Miller, K.J. Bitterman, N.R. Wall, B. Hekking, B. Kessler, K.T. Howitz, M. Gorospe, R. de Cabo, D.A. Sinclair, Calorie restriction promotes mammalian cell survival by inducing the SIRT1 deacetylase, Science 305 (2004) 390-392.

[56] E. Nisoli, C. Tonello, A. Cardile, V. Cozzi, R. Bracale, L. Tedesco, S. Falcone, A. Valerio, O. Cantoni, E. Clementi, S. Moncada, M.O. Carruba, Calorie restriction promotes mitochondrial biogenesis by inducing the expression of eNOS, Science 310 (2005) 314-317.

[57] G. Lopez-Lluch, N. Hunt, B. Jones, M. Zhu, H. Jamieson, S. Hilmer, M.V. Cascajo, J Allard, D.K. Ingram, P. Navas, R. de Cabo, Calorie restriction induces mitochondrial biogenesis and bioenergetic efficiency, Proc. Natl. Acad. Sci. U. S. A. 103 (2006) 1768-1773.

[58] A.E. Civitarese, S. Carling, L.K. Heilbronn, M.H. Hulver, B. Ukropcova, W.A Deutsch, S.R. Smith, E. Ravussin, Calorie restriction increases muscle mitochondrial biogenesis in healthy humans, PLoS Med. 4 (2007) e76.

[59] C.R. Hancock, D.H. Han, K. Higashida, S.H. Kim, J.O. Holloszy, Does calorie restriction induce mitochondrial biogenesis? A reevaluation, FASEB J. 25 (2011) 785-791.

[60] M. Lagouge, C. Argmann, Z. Gerhart-Hines, H. Meziane, C. Lerin, F. Daussin, N. Messadeq, J. Milne, P. Lambert, P. Elliott, B. Geny, M. Laakso, P. Puigserver, J. Auwerx, Resveratrol improves mitochondrial function and protects against metabolic disease by activating SIRT1 and PGC-1alpha, Cell 127 (2006) 1109-1122.

[61] A. Csiszar, N. Labinskyy, J.T. Pinto, P. Ballabh, H. Zhang, G. Losonczy, K. Pearson, R de Cabo, P. Pacher, C. Zhang, Z. Ungvari, Resveratrol induces mitochondrial biogenesis in endothelial cells, Am. J. Physiol. Heart Circ. Physiol. 297 (2009) $\mathrm{H} 13-\mathrm{H} 20$.

[62] J.A. Funk, S. Odejinmi, R.G. Schnellmann, SRT1720 induces mitochondrial biogenesis and rescues mitochondrial function after oxidant injury in renal proximal tubule cells, J. Pharmacol. Exp. Ther. 333 (2010) 593-601.

[63] J.H. Um, S.J. Park, H. Kang, S. Yang, M. Foretz, M.W. McBurney, M.K. Kim, B Viollet, J.H. Chung, AMP-activated protein kinase-deficient mice are resistant to the metabolic effects of resveratrol, Diabetes 59 (2010) 554-563.

[64] S.J. Park, F. Ahmad, A. Philp, K. Baar, T. Williams, H. Luo, H. Ke, H. Rehmann, R. Taussig, A.L. Brown, M.K. Kim, M.A. Beaven, A.B. Burgin, V. Manganiello, J.H. Chung, Resveratrol ameliorates aging-related metabolic phenotypes by inhibiting cAMP phosphodiesterases, Cell 148 (2012) 421-433.

[65] N.L. Price, A.P. Gomes, A.J. Ling, F.V. Duarte, A. Martin-Montalvo, B.J. North, B. Agarwal, L. Ye, G. Ramadori, J.S. Teodoro, B.P. Hubbard, A.T. Varela, J.G. Davis, B. Varamini, A. Hafner, R. Moaddel, A.P. Rolo, R. Coppari, C.M. Palmeira, R. de Cabo, J.A. Baur, D.A. Sinclair, SIRT1 is required for AMPK activation and the beneficial effects of resveratrol on mitochondrial function, Cell Metab. 15 (2012) 675-690.

[66] B. Dasgupta, J. Milbrandt, Resveratrol stimulates AMP kinase activity in neurons, Proc. Natl. Acad. Sci. U. S. A. 104 (2007) 7217-7222.

[67] F. Lan, J.M. Cacicedo, N. Ruderman, Y. Ido, SIRT1 modulation of the acetylation status, cytosolic localization, and activity of LKB1. Possible role in AMP-activated protein kinase activation, J. Biol. Chem. 283 (2008) 27628-27635.

[68] P. Wareski, A. Vaarmann, V. Choubey, D. Safiulina, J. Liiv, M. Kuum, A. Kaasik, PGC-1\{alpha\} and PGC-1 beta\} regulate mitochondrial density in neurons, J. Biol. Chem. 284 (2009) 21379-21385.

[69] M.O. Dietrich, C. Antunes, G. Geliang, Z.W. Liu, E. Borok, Y. Nie, A.W. Xu, D.O Souza, Q. Gao, S. Diano, X.B. Gao, T.L. Horvath, Agrp neurons mediate Sirt1's action on the melanocortin system and energy balance: roles for Sirt1 in neuronal firing and synaptic plasticity, J. Neurosci. 30 (2010) 11815-11825.

[70] A.W. Jones, Z. Yao, J.M. Vicencio, A. Karkucinska-Wieckowska, G. Szabadkai, PGC-1 family coactivators and cell fate: roles in cancer, neurodegeneration, cardiovascular disease and retrograde mitochondria-nucleus signalling, Mitochondrion 12 (2012) 86-99.

[71] C. Ciron, S. Lengacher, J. Dusonchet, P. Aebischer, B.L. Schneider, Sustained expression of PGC-1alpha in the rat nigrostriatal system selectively impairs dopaminergic function, Hum. Mol. Genet. 21 (2012) 1861-1876.

[72] J. Kim, J.P. Moody, C.K. Edgerly, O.L. Bordiuk, K. Cormier, K. Smith, M.F. Beal, R.J. Ferrante, Mitochondrial loss, dysfunction and altered dynamics in Huntington's disease, Hum. Mol. Genet. 19 (2010) 3919-3935.

[73] J. Lin, P.H. Wu, P.T. Tarr, K.S. Lindenberg, J. St-Pierre, C.Y. Zhang, V.K. Mootha, S Jager, C.R. Vianna, R.M. Reznick, L. Cui, M. Manieri, M.X. Donovan, Z. Wu, M.P. Cooper, M.C. Fan, L.M. Rohas, A.M. Zavacki, S. Cinti, G.I. Shulman, B.B. Lowell, D. Krainc, B.M. Spiegelman, Defects in adaptive energy metabolism with CNS-linked hyperactivity in PGC-1alpha null mice, Cell 119 (2004) 121-135.

[74] J.M. Oliveira, Nature and cause of mitochondrial dysfunction in Huntington's disease: focusing on huntingtin and the striatum, J. Neurochem. 114 (2010) $1-12$.

[75] M.J. Calkins, M. Manczak, P. Mao, U. Shirendeb, P.H. Reddy, Impaired mitochondria biogenesis, defective axonal transport of mitochondria, abnormal mitochondrial dynamics and synaptic degeneration in a mouse model of Alzheimer's disease, Hum. Mol. Genet. 20 (2011) 4515-4529. 
[76] K. Hirai, G. Aliev, A. Nunomura, H. Fujioka, R.L. Russell, C.S. Atwood, A.B. Johnson, Y. Kress, H.V. Vinters, M. Tabaton, S. Shimohama, A.D. Cash, S.L. Siedlak, P.L. Harris, P.K. Jones, R.B. Petersen, G. Perry, M.A. Smith, Mitochondrial abnormalities in Alzheimer's disease, J. Neurosci. 21 (2001) 3017-3023.

[77] B. Sheng, X. Wang, B. Su, H.G. Lee, G. Casadesus, G. Perry, X. Zhu, Impaired mitochondrial biogenesis contributes to mitochondrial dysfunction in Alzheimer's disease, J. Neurochem. 120 (2012) 419-429.

[78] J.H. Shin, H.S. Ko, H. Kang, Y. Lee, Y.I. Lee, O. Pletinkova, J.C. Troconso, V.L. Dawson, T.M. Dawson, PARIS (ZNF746) repression of PGC-1alpha contributes to neurodegeneration in Parkinson's disease, Cell 144 (2011) 689-702.

[79] J. Clark, S. Reddy, K. Zheng, R.A. Betensky, D.K. Simon, Association of PGC-1alpha polymorphisms with age of onset and risk of Parkinson's disease, BMC Med. Genet. 12 (2011) 69

[80] P. Weydt, S.M. Soyal, C. Gellera, S. Didonato, C. Weidinger, H. Oberkofler, G.B. Landwehrmeyer, W. Patsch, The gene coding for PGC-1alpha modifies age at onset in Huntington's Disease, Mol. Neurodegener. 4 (2009) 3.

[81] E. Taherzadeh-Fard, C. Saft, J. Andrich, S. Wieczorek, L. Arning, PGC-1alpha as modifier of onset age in Huntington disease, Mol. Neurodegener. 4 (2009) 10.

[82] H.V. Che, S. Metzger, E. Portal, C. Deyle, O. Riess, H.P. Nguyen, Localization of sequence variations in PGC-1alpha influence their modifying effect in Huntington disease, Mol. Neurodegener. 6 (2011) 1.

[83] E.M. Ramos, J.C. Latourelle, J.H. Lee, T. Gillis, J.S. Mysore, F. Squitieri, A. Di Pardo, S. Di Donato, M.R. Hayden, P.J. Morrison, M. Nance, C.A. Ross, R.L. Margolis, E. Gomez-Tortosa, C. Ayuso, O. Suchowersky, R.J. Trent, E. McCusker, A. Novelletto M. Frontali, R. Jones, T. Ashizawa, S. Frank, M.H. Saint-Hilaire, S.M. Hersch, H.D. Rosas, D. Lucente, M.B. Harrison, A. Zanko, K. Marder, J.F. Gusella, J.M. Lee, I. Alonso, J. Sequeiros, R.H. Myers, M.E. Macdonald, Population stratification may bias analysis of PGC-1alpha as a modifier of age at Huntington disease motor onset, Hum. Genet. 131 (2012) 1833-1840.

[84] X. Kong, R. Wang, Y. Xue, X. Liu, H. Zhang, Y. Chen, F. Fang, Y. Chang, Sirtuin 3, a new target of PGC-1alpha, plays an important role in the suppression of ROS and mitochondrial biogenesis, PLoS One 5 (2010) e11707.

[85] Y. Yang, H. Cimen, M.J. Han, T. Shi, J.H. Deng, H. Koc, O.M. Palacios, L. Montier, Y. Bai, Q. Tong, E.C. Koc, NAD +-dependent deacetylase SIRT3 regulates mitochondrial protein synthesis by deacetylation of the ribosomal protein MRPL10, J. Biol. Chem. 285 (2010) 7417-7429.

[86] W. Song, Y. Song, B. Kincaid, B. Bossy, E. Bossy-Wetzel, Mutant SOD1(G93A) triggers mitochondrial fragmentation in spinal cord motor neurons: neuroprotection by SIRT3 and PGC-1alpha, Neurobiol. Dis. 51 (2012) 72-81.

[87] D.C. Chan, Mitochondrial fusion and fission in mammals, Annu. Rev. Cell Dev. Biol. 22 (2006) 79-99.

[88] H. Chen, J.M. McCaffery, D.C. Chan, Mitochondrial fusion protects against neurodegeneration in the cerebellum, Cell 130 (2007) 548-562.

[89] N. Taguchi, N. Ishihara, A. Jofuku, T. Oka, K. Mihara, Mitotic phosphorylation of dynamin-related GTPase Drp1 participates in mitochondrial fission, J. Biol Chem. 282 (2007) 11521-11529.

[90] G. Twig, A. Elorza, A.J. Molina, H. Mohamed, J.D. Wikstrom, G. Walzer, L. Stiles, S.E. Haigh, S. Katz, G. Las, J. Alroy, M. Wu, B.F. Py, J. Yuan, J.T. Deeney, B.E. Corkey, O.S. Shirihai, Fission and selective fusion govern mitochondrial segregation and elimination by autophagy, EMBO J. 27 (2008) 433-446.

[91] Z. Li, K. Okamoto, Y. Hayashi, M. Sheng, The importance of dendritic mitochondria in the morphogenesis and plasticity of spines and synapses, Cell 119 (2004) 873-887.

[92] N. Ishihara, M. Nomura, A. Jofuku, H. Kato, S.O. Suzuki, K. Masuda, H. Otera, Y. Nakanishi, I. Nonaka, Y. Goto, N. Taguchi, H. Morinaga, M. Maeda, R. Takayanagi, S. Yokota, K. Mihara, Mitochondrial fission factor Drp1 is essential for embryonic development and synapse formation in mice, Nat. Cell Biol. 11 (2009) 958-966.

[93] Y. Kageyama, Z. Zhang, R. Roda, M. Fukaya, J. Wakabayashi, N. Wakabayashi, T.W. Kensler, P.H. Reddy, M. Iijima, H. Sesaki, Mitochondrial division ensures the survival of postmitotic neurons by suppressing oxidative damage, J. Cell Biol. 197 (2012) 535-551.

[94] Z. Song, M. Ghochani, J.M. McCaffery, T.G. Frey, D.C. Chan, Mitofusins and OPA1 mediate sequential steps in mitochondrial membrane fusion, Mol. Biol. Cell 20 (2009) 3525-3532.

[95] H. Chen, S.A. Detmer, A.J. Ewald, E.E. Griffin, S.E. Fraser, D.C. Chan, Mitofusins Mfn1 and Mfn2 coordinately regulate mitochondrial fusion and are essential for embryonic development, J. Cell Biol. 160 (2003) 189-200.

[96] T. Koshiba, S.A. Detmer, J.T. Kaiser, H. Chen, J.M. McCaffery, D.C. Chan, Structural basis of mitochondrial tethering by mitofusin complexes, Science 305 (2004) 858-862.

[97] S. Cipolat, T. Rudka, D. Hartmann, V. Costa, L. Serneels, K. Craessaerts, K. Metzger C. Frezza, W. Annaert, L. D'Adamio, C. Derks, T. Dejaegere, L. Pellegrini, R D'Hooge, L. Scorrano, B. De Strooper, Mitochondrial rhomboid PARL regulates cytochrome c release during apoptosis via OPA1-dependent cristae remodeling Cell 126 (2006) 163-175.

[98] S. Meeusen, R. DeVay, J. Block, A. Cassidy-Stone, S. Wayson, J.M. McCaffery, J Nunnari, Mitochondrial inner-membrane fusion and crista maintenance requires the dynamin-related GTPase Mgm1, Cell 127 (2006) 383-395.

[99] R.M. DeVay, L. Dominguez-Ramirez, L.L. Lackner, S. Hoppins, H. Stahlberg, J. Nunnari, Coassembly of Mgm1 isoforms requires cardiolipin and mediates mitochondrial inner membrane fusion, J. Cell Biol. 186 (2009) 793-803.

[100] S. Zuchner, I.V. Mersiyanova, M. Muglia, N. Bissar-Tadmouri, J. Rochelle, E.L Dadali, M. Zappia, E. Nelis, A. Patitucci, J. Senderek, Y Parman, O. Evgrafov, P.D. Jonghe, Y. Takahashi, S. Tsuji, M.A. Pericak-Vance, A. Quattrone, E. Battaloglu, A.V. Polyakov, V. Timmerman, J.M. Schroder, J.M. Vance, Mutations in the mitochondrial GTPase mitofusin 2 cause Charcot-Marie-Tooth neuropathy type 2A Nat. Genet. 36 (2004) 449-451.
[101] H. Otera, K. Mihara, Molecular mechanisms and physiologic functions of mitochondrial dynamics, J. Biochem. 149 (2011) 241-251.

[102] E. Ingerman, E.M. Perkins, M. Marino, J.A. Mears, J.M. McCaffery, J.E. Hinshaw, J. Nunnari, Dnm1 forms spirals that are structurally tailored to fit mitochondria, J. Cell Biol. 170 (2005) 1021-1027.

[103] H.R. Waterham, J. Koster, C.W. van Roermund, P.A. Mooyer, R.J. Wanders, J.V. Leonard, A lethal defect of mitochondrial and peroxisomal fission, N. Engl. J. Med. 356 (2007) 1736-1741.

[104] H. Otera, C. Wang, M.M. Cleland, K. Setoguchi, S. Yokota, R.J. Youle, K. Mihara, Mff is an essential factor for mitochondrial recruitment of Drp1 during mitochondrial fission in mammalian cells, J. Cell Biol. 191 (2010) 1141-1158.

[105] J. Zhao, T. Liu, S. Jin, X. Wang, M. Qu, P. Uhlen, N. Tomilin, O. Shupliakov, U. Lendahl, M. Nister, Human MIEF1 recruits Drp1 to mitochondrial outer membranes and promotes mitochondrial fusion rather than fission, EMBO J. 30 (2011) 2762-2778.

[106] C.S. Palmer, L.D. Osellame, D. Laine, O.S. Koutsopoulos, A.E. Frazier, M.T. Ryan, MiD49 and MiD51, new components of the mitochondrial fission machinery, EMBO Rep. 12 (2011) 565-573.

[107] B. Oettinghaus, M. Licci, L. Scorrano, S. Frank, Less than perfect divorces: dysregulated mitochondrial fission and neurodegeneration, Acta Neuropathol. 123 (2012) 189-203.

[108] K. Onoue, A. Jofuku, R. Ban-Ishihara, T. Ishihara, M. Maeda, T. Koshiba, T. Itoh, M. Fukuda, H. Otera, T. Oka, H. Takano, N. Mizushima, K. Mihara, N. Ishihara, Fis1 acts as mitochondrial recruitment factor for TBC1D15 that involved in regulation of mitochondrial morphology, J. Cell Sci. 126 (2012) 176-185.

[109] J.S. Lee, Y.G. Yoon, S.H. Yoo, N.Y. Jeong, S.H. Jeong, S.Y. Lee, D.I. Jung, S.Y. Jeong, Y.H. Yoo, Histone deacetylase inhibitors induce mitochondrial elongation, J. Cell. Physiol. 227 (2012) 2856-2869.

[110] Q Zhou, A.T. Agoston, P. Atadja, W.G. Nelson, N.E. Davidson, Inhibition of histone deacetylases promotes ubiquitin-dependent proteasomal degradation of DNA methyltransferase 1 in human breast cancer cells, Mol. Cancer Res. 6 (2008) 873-883.

[111] H.T. Kang, E.S. Hwang, Nicotinamide enhances mitochondria quality through autophagy activation in human cells, Aging Cell 8 (2009) 426-438.

[112] S.Y. Jang, H.T. Kang, E.S. Hwang, Nicotinamide-induced mitophagy: event mediated by high NAD +/NADH ratio and SIRT1 protein activation, J. Biol. Chem. 287 (2012) 19304-19314.

[113] J. Magrane, M.A. Sahawneh, S. Przedborski, A.G. Estevez, G. Manfredi, Mitochondrial dynamics and bioenergetic dysfunction is associated with synaptic alterations in mutant SOD1 motor neurons, J. Neurosci. 32 (2012) 229-242.

[114] J. Magrane, I. Hervias, M.S. Henning, M. Damiano, H. Kawamata, G. Manfredi, Mutant SOD1 in neuronal mitochondria causes toxicity and mitochondrial dynamics abnormalities, Hum. Mol. Genet. 18 (2009) 4552-4564.

[115] M.L. Tradewell, L.A. Cooper, S. Minotti, H.D. Durham, Calcium dysregulation, mitochondrial pathology and protein aggregation in a culture model of amyotrophic lateral sclerosis: mechanistic relationship and differential sensitivity to intervention, Neurobiol. Dis. 42 (2011) 265-275.

[116] C. Vande Velde, K.K. McDonald, Y. Boukhedimi, M. McAlonis-Downes, C.S. Lobsiger, S. Bel Hadj, A. Zandona, J.P. Julien, S.B. Shah, D.W. Cleveland, Misfolded SOD1 associated with motor neuron mitochondria alters mitochondrial shape and distribution prior to clinical onset, PLoS One 6 (2011) e22031.

[117] A. Ferri, P. Fiorenzo, M. Nencini, M. Cozzolino, M.G. Pesaresi, C. Valle, S. Sepe, S. Moreno, M.T. Carri, Glutaredoxin 2 prevents aggregation of mutant SOD1 in mitochondria and abolishes its toxicity, Hum. Mol. Genet. 19 (2010) 4529-4542.

[118] X. Wang, B. Su, H.G. Lee, X. Li, G. Perry, M.A. Smith, X. Zhu, Impaired balance of mitochondrial fission and fusion in Alzheimer's disease, J. Neurosci. 29 (2009) 9090-9103.

[119] H. Chen, D.C. Chan, Mitochondrial dynamics - fusion, fission, movement, and mitophagy - in neurodegenerative diseases, Hum. Mol. Genet. 18 (2009) R169-R176.

[120] M. Cui, X. Tang, W.V. Christian, Y. Yoon, K. Tieu, Perturbations in mitochondrial dynamics induced by human mutant PINK1 can be rescued by the mitochondrial division inhibitor mdivi-1, J. Biol. Chem. 285 (2010) 11740-11752.

[121] H. Wang, P. Song, L. Du, W. Tian, W. Yue, M. Liu, D. Li, B. Wang, Y.Zhu, C. Cao, J. Zhou, Q. Chen, Parkin ubiquitinates Drp1 for proteasome-dependent degradation: implication of dysregulated mitochondrial dynamics in Parkinson disease, J. Biol. Chem. 286 (2011) 11649-11658.

[122] U. Shirendeb, A.P. Reddy, M. Manczak, M.J. Calkins, P. Mao, D.A. Tagle, P.H. Reddy, Abnormal mitochondrial dynamics, mitochondrial loss and mutant huntingtin oligomers in Huntington's disease: implications for selective neuronal damage, Hum. Mol. Genet. 20 (2011) 1438-1455.

[123] V. Costa, M. Giacomello, R. Hudec, R. Lopreiato, G. Ermak, D. Lim, W. Malorni, KJ. Davies, E. Carafoli, L. Scorrano, Mitochondrial fission and cristae disruption increase the response of cell models of Huntington's disease to apoptotic stimuli, EMBO Mol. Med. 2 (2010) 490-503.

[124] G.M. Cereghetti, A. Stangherlin, O. Martins de Brito, C.R. Chang, C. Blackstone, P. Bernardi, L. Scorrano, Dephosphorylation by calcineurin regulates translocation of Drp1 to mitochondria, Proc. Natl. Acad. Sci. U. S. A. 105 (2008) $15803-15808$

[125] J.M. Oliveira, R.N. Lightowlers, Could successful (mitochondrial) networking help prevent Huntington's disease? EMBO Mol. Med. 2 (2010) 487-489.

[126] S. Strack, J.T. Cribbs, Allosteric modulation of Drp1 mechanoenzyme assembly and mitochondrial fission by the variable domain, J. Biol. Chem. 287 (2012) 10990-11001.

[127] W. Song, J. Chen, A. Petrilli, G. Liot, E. Klinglmayr, Y. Zhou, P. Poquiz, J. Tjong, M.A. Pouladi, M.R. Hayden, E. Masliah, M. Ellisman, I. Rouiller, R. Schwarzenbacher, B. Bossy, G. Perkins, E. Bossy-Wetzel, Mutant huntingtin binds the mitochondrial 
fission GTPase dynamin-related protein-1 and increases its enzymatic activity, Nat. Med. 17 (2011) 377-382.

[128] U.P. Shirendeb, M.J. Calkins, M. Manczak, V. Anekonda, B. Dufour, J.L. McBride, P. Mao, P.H. Reddy, Mutant huntingtin's interaction with mitochondrial protein Drp1 impairs mitochondrial biogenesis and causes defective axonal transport and synaptic degeneration in Huntington's disease, Hum. Mol. Genet. 21 (2012) 406-420.

[129] M. Manczak, M.J. Calkins, P.H. Reddy, Impaired mitochondrial dynamics and abnormal interaction of amyloid beta with mitochondrial protein Drp1 in neurons from patients with Alzheimer's disease: implications for neuronal damage, Hum. Mol. Genet. 20 (2011) 2495-2509.

[130] J. Grohm, S.W. Kim, U. Mamrak, S. Tobaben, A. Cassidy-Stone, J. Nunnari, N. Plesnila, C. Culmsee, Inhibition of Drp1 provides neuroprotection in vitro and in vivo, Cell Death Differ. 19 (2012) 1446-1458.

[131] Z.H. Sheng, Q. Cai, Mitochondrial transport in neurons: impact on synaptic homeostasis and neurodegeneration, Nat. Rev. Neurosci. 13 (2012) 77-93.

[132] P.J. Hollenbeck, W.M. Saxton, The axonal transport of mitochondria, J. Cell Sci. 118 (2005) 5411-5419.

[133] Q. Cai, M.L. Davis, Z.H. Sheng, Regulation of axonal mitochondrial transport and its impact on synaptic transmission, Neurosci. Res. 70 (2011) 9-15.

[134] J.S. Kang, J.H. Tian, P.Y. Pan, P. Zald, C. Li, C. Deng, Z.H. Sheng, Docking of axonal mitochondria by syntaphilin controls their mobility and affects short-term facilitation, Cell 132 (2008) 137-148.

[135] J.W. Hammond, D. Cai, K.J. Verhey, Tubulin modifications and their cellular functions, Curr. Opin. Cell Biol. 20 (2008) 71-76.

[136] C. Janke, M. Kneussel, Tubulin post-translational modifications: encoding functions on the neuronal microtubule cytoskeleton, Trends Neurosci. 33 (2010) 362-372.

[137] N.A. Reed, D. Cai, T.L. Blasius, G.T. Jih, E. Meyhofer, J. Gaertig, K.J. Verhey, Microtubule acetylation promotes kinesin-1 binding and transport, Curr. Biol. 16 (2006) 2166-2172.

[138] J.P. Dompierre, J.D. Godin, B.C. Charrin, F.P. Cordelieres, S.J. King, S. Humbert, F. Saudou, Histone deacetylase 6 inhibition compensates for the transport deficit in Huntington's disease by increasing tubulin acetylation, J. Neurosci. 27 (2007) 3571-3583.

[139] C. Creppe, M. Buschbeck, Elongator: an ancestral complex driving transcription and migration through protein acetylation, J. Biomed. Biotechnol. 2011 (2011) 924898.

[140] T. Shida, J.G. Cueva, Z. Xu, M.B. Goodman, M.V. Nachury, The major alpha-tubulin K40 acetyltransferase alphaTAT1 promotes rapid ciliogenesis and efficient mechanosensation, Proc. Natl. Acad. Sci. U. S. A. 107 (2010) 21517-21522.

[141] C. Hubbert, A. Guardiola, R. Shao, Y. Kawaguchi, A. Ito, A. Nixon, M. Yoshida, X.F. Wang, T.P. Yao, HDAC6 is a microtubule-associated deacetylase, Nature 417 (2002) 455-458

[142] B.J. North, B.L. Marshall, M.T. Borra, J.M. Denu, E. Verdin, The human Sir2 ortholog, SIRT2, is an NAD+-dependent tubulin deacetylase, Mol. Cell 11 (2003) 437-444.

[143] Y. Zhang, N. Li, C. Caron, G. Matthias, D. Hess, S. Khochbin, P. Matthias, HDAC-6 interacts with and deacetylates tubulin and microtubules in vivo, EMBO J. 22 (2003) 1168-1179.

[144] F. Nahhas, S.C. Dryden, J. Abrams, M.A. Tainsky, Mutations in SIRT2 deacetylase which regulate enzymatic activity but not its interaction with HDAC6 and tubulin, Mol. Cell. Biochem. 303 (2007) 221-230.

[145] W. Li, B. Zhang, J. Tang, Q. Cao, Y. Wu, C. Wu, J. Guo, E.A. Ling, F. Liang, Sirtuin 2, a mammalian homolog of yeast silent information regulator-2 longevity regulator, is an oligodendroglial protein that decelerates cell differentiation through deacetylating alpha-tubulin, J. Neurosci. 27 (2007) 2606-2616.

[146] R. Pandithage, R. Lilischkis, K. Harting, A. Wolf, B. Jedamzik, J. Luscher-Firzlaff, J. Vervoorts, E. Lasonder, E. Kremmer, B. Knoll, B. Luscher, The regulation of SIRT2 function by cyclin-dependent kinases affects cell motility, J. Cell Biol. 180 (2008) 915-929.

[147] R. Luthi-Carter, D.M. Taylor, J. Pallos, E. Lambert, A. Amore, A. Parker, H. Moffitt, D.L. Smith, H. Runne, O. Gokce, A. Kuhn, Z. Xiang, M.M. Maxwell, S.A. Reeves, G.P. Bates, C. Neri, L.M. Thompson, J.L. Marsh, A.G. Kazantsev, SIRT2 inhibition achieves neuroprotection by decreasing sterol biosynthesis, Proc. Natl. Acad. Sci. U. S. A. 107 (2010) 7927-7932.

[148] Y. Zhang, S. Kwon, T. Yamaguchi, F. Cubizolles, S. Rousseaux, M. Kneissel, C. Cao, N. Li, H.L. Cheng, K. Chua, D. Lombard, A. Mizeracki, G. Matthias, F.W. Alt, S. Khochbin, P. Matthias, Mice lacking histone deacetylase 6 have hyperacetylated tubulin but are viable and develop normally, Mol. Cell. Biol. 28 (2008) 1688-1701.

[149] N. Govindarajan, P. Rao, S. Burkhardt, F. Sananbenesi, O.M. Schluter, F. Bradke, J. Lu, A. Fischer, Reducing HDAC6 ameliorates cognitive deficits in a mouse model for Alzheimer's disease, EMBO Mol. Med. 5 (2013) 52-63.

[150] T.F. Outeiro, E. Kontopoulos, S.M. Altmann, I. Kufareva, K.E. Strathearn, A.M. Amore, C.B. Volk, M.M. Maxwell, J.C. Rochet, P.J. McLean, A.B. Young, R. Abagyan, M.B. Feany, B.T. Hyman, A.G. Kazantsev, Sirtuin 2 inhibitors rescue alphasynuclein-mediated toxicity in models of Parkinson's disease, Science 317 (2007) 516-519.

[151] M. Valenza, E. Cattaneo, Neuroprotection and brain cholesterol biosynthesis in Huntington's disease, Proc. Natl. Acad. Sci. U. S. A. 107 (2010) E143, (author reply 144).

[152] S. Chen, G.C. Owens, H. Makarenkova, D.B. Edelman, HDAC6 regulates mitochondrial transport in hippocampal neurons, PLoS One 5 (2010) e10848.

[153] Y. Rui, P. Tiwari, Z. Xie, J.Q. Zheng, Acute impairment of mitochondrial trafficking by beta-amyloid peptides in hippocampal neurons, J. Neurosci. 26 (2006) 10480-10487.

[154] H. Decker, K.Y. Lo, S.M. Unger, S.T. Ferreira, M.A. Silverman, Amyloid-beta peptide oligomers disrupt axonal transport through an NMDA receptor-dependent mechanism that is mediated by glycogen synthase kinase 3beta in primary cultured hippocampal neurons, J. Neurosci. 30 (2010) 9166-9171.

[155] B. Hempen, J.P. Brion, Reduction of acetylated alpha-tubulin immunoreactivity in neurofibrillary tangle-bearing neurons in Alzheimer's disease, J. Neuropathol. Exp. Neurol. 55 (1996) 964-972.

[156] H. Ding, P.J. Dolan, G.V. Johnson, Histone deacetylase 6 interacts with the microtubule-associated protein tau, J. Neurochem. 106 (2008) 2119-2130.

[157] C. Kim, H. Choi, E.S. Jung, W. Lee, S. Oh, N.L. Jeon, I. Mook-Jung, HDAC6 inhibitor blocks amyloid beta-induced impairment of mitochondrial transport in hippocampal neurons, PLoS One 7 (2012) e42983.

[158] C. d'Ydewalle, J. Krishnan, D.M. Chiheb, P. Van Damme, J. Irobi, A.P. Kozikowski, P. Vanden Berghe, V. Timmerman, W. Robberecht, L. Van Den Bosch, HDAC6 inhibitors reverse axonal loss in a mouse model of mutant HSPB1-induced CharcotMarie-Tooth disease, Nat. Med. 17 (2011) 968-974.

[159] J.Y. Kim, S. Shen, K. Dietz, Y. He, O. Howell, R. Reynolds, P. Casaccia, HDAC1 nuclear export induced by pathological conditions is essential for the onset of axonal damage, Nat. Neurosci. 13 (2010) 180-189.

[160] J.M. Oliveira, S. Chen, S. Almeida, R. Riley, J. Goncalves, C.R. Oliveira, M.R Hayden, D.G. Nicholls, L.M. Ellerby, A.C. Rego, Mitochondrial-dependent Ca2 + handling in Huntington's disease striatal cells: effect of histone deacetylase inhibitors, J. Neurosci. 26 (2006) 11174-11186.

[161] G. Twig, O.S. Shirihai, The interplay between mitochondrial dynamics and mitophagy, Antioxid. Redox Signal. 14 (2011) 1939-1951.

[162] S.M. Jin, M. Lazarou, C. Wang, L.A. Kane, D.P. Narendra, R.J. Youle, Mitochondrial membrane potential regulates PINK1 import and proteolytic destabilization by PARL, J. Cell Biol. 191 (2010) 933-942.

[163] S. Geisler, K.M. Holmstrom, D. Skujat, F.C. Fiesel, O.C. Rothfuss, P.J. Kahle, W. Springer, PINK1/Parkin-mediated mitophagy is dependent on VDAC1 and p62/SQSTM1, Nat. Cell Biol. 12 (2010) 119-131.

[164] X. Wang, D. Winter, G. Ashrafi, J. Schlehe, Y.L. Wong, D. Selkoe, S. Rice, J Steen, M.J. LaVoie, T.L. Schwarz, PINK1 and Parkin target Miro for phosphorylation and degradation to arrest mitochondrial motility, Cell 147 (2011) 893-906.

[165] S. Liu, T. Sawada, S. Lee, W. Yu, G. Silverio, P. Alapatt, I. Millan, A. Shen, W. Saxton, T. Kanao, R. Takahashi, N. Hattori, Y. Imai, B. Lu, Parkinson's diseaseassociated kinase PINK1 regulates Miro protein level and axonal transport of mitochondria, PLoS Genet. 8 (2012) e1002537.

[166] M.E. Gegg, J.M. Cooper, K.Y. Chau, M. Rojo, A.H. Schapira, J.W. Taanman, Mitofusin 1 and mitofusin 2 are ubiquitinated in a PINK1/parkin-dependent manner upon induction of mitophagy, Hum. Mol. Genet. 19 (2010) 4861-4870.

[167] J.Y. Lee, Y. Nagano, J.P. Taylor, K.L. Lim, T.P. Yao, Disease-causing mutations in parkin impair mitochondrial ubiquitination, aggregation, and HDAC6-dependent mitophagy, J. Cell Biol. 189 (2010) 671-679.

[168] R.J. Youle, D.P. Narendra, Mechanisms of mitophagy, Nat. Rev. Mol. Cell Biol. 12 (2011) 9-14.

[169] W.X. Ding, X.M. Yin, Mitophagy: mechanisms, pathophysiological roles, and analysis, Biol. Chem. 393 (2012) 547-564.

[170] J.Y. Lee, H. Koga, Y. Kawaguchi, W. Tang, E. Wong, Y.S. Gao, U.B. Pandey, S. Kaushik, E. Tresse, J. Lu, J.P. Taylor, A.M. Cuervo, T.P. Yao, HDAC6 controls autophagosome maturation essential for ubiquitin-selective quality-control autophagy, EMBO J. 29 (2010) 969-980.

[171] H. Ouyang, Y.O. Ali, M. Ravichandran, A. Dong, W. Qiu, F. MacKenzie, S Dhe-Paganon, C.H. Arrowsmith, R.G. Zhai, Protein aggregates are recruited to aggresome by histone deacetylase 6 via unanchored ubiquitin C termini, J. Biol. Chem. 287 (2012) 2317-2327.

[172] Y. Kawaguchi, J.J. Kovacs, A. McLaurin, J.M. Vance, A. Ito, T.P. Yao, The deacetylase HDAC6 regulates aggresome formation and cell viability in response to misfolded protein stress, Cell 115 (2003) 727-738.

[173] A. Iwata, B.E. Riley, J.A. Johnston, R.R. Kopito, HDAC6 and microtubules are required for autophagic degradation of aggregated huntingtin, J. Biol. Chem. 280 (2005) 40282-40292.

[174] U.B. Pandey, Z. Nie, Y. Batlevi, B.A. McCray, G.P. Ritson, N.B. Nedelsky, S.L. Schwartz, N.A. DiProspero, M.A. Knight, O. Schuldiner, R. Padmanabhan, M. Hild D.L. Berry, D. Garza, C.C. Hubbert, T.P. Yao, E.H. Baehrecke, J.P. Taylor, HDAC6 rescues neurodegeneration and provides an essential link between autophagy and the UPS, Nature 447 (2007) 859-863.

[175] S.J. Haggarty, K.M. Koeller, J.C. Wong, C.M. Grozinger, S.L. Schreiber, Domain-selective small-molecule inhibitor of histone deacetylase 6 (HDAC6)-mediated tubulin deacetylation, Proc. Natl. Acad. Sci. U. S. A. 100 (2003) 4389-4394.

[176] Y. Zhang, M. Zhang, H. Dong, S. Yong, X. Li, N. Olashaw, P.A. Kruk, J.Q. Cheng, W. Bai, J. Chen, S.V. Nicosia, X. Zhang, Deacetylation of cortactin by SIRT1 promotes cell migration, Oncogene 28 (2009) 445-460.

177] G. Li, H. Jiang, M. Chang, H. Xie, L. Hu, HDAC6 alpha-tubulin deacetylase: a potential therapeutic target in neurodegenerative diseases, J. Neurol. Sci. 304 (2011) 1-8.

[178] C.A. Ross, M.A. Poirier, Protein aggregation and neurodegenerative disease, Nat. Med. 10 (2004) S10-S17, (Suppl.)

[179] C. Vives-Bauza, S. Przedborski, Mitophagy: the latest problem for Parkinson's disease, Trends Mol. Med. 17 (2011) 158-165.

[180] D. Narendra, A. Tanaka, D.F. Suen, R.J. Youle, Parkin is recruited selectively to impaired mitochondria and promotes their autophagy, J. Cell Biol. 183 (2008) 795-803.

[181] P.I. Moreira, S.L. Siedlak, X. Wang, M.S. Santos, C.R. Oliveira, M. Tabaton, A. Nunomura, L.I. Szweda, G. Aliev, M.A. Smith, X. Zhu, G. Perry, Autophagocytosis of mitochondria is prominent in Alzheimer disease, J. Neuropathol. Exp. Neurol. 66 (2007) 525-532. 
[182] P.I. Moreira, S.L. Siedlak, X. Wang, M.S. Santos, C.R. Oliveira, M. Tabaton, A. Nunomura, L.I. Szweda, G. Aliev, M.A. Smith, X. Zhu, G. Perry, Increased autophagic degradation of mitochondria in Alzheimer disease, Autophagy 3 (2007) 614-615.

[183] R.X. Santos, S.C. Correia, X. Wang, G. Perry, M.A. Smith, P.I. Moreira, X. Zhu, A synergistic dysfunction of mitochondrial fission/fusion dynamics and mitophagy in Alzheimer's disease, J. Alzheimers Dis. 20 (Suppl. 2) (2010) S401-S412.

[184] P.J. Khandelwal, A.M. Herman, H.S. Hoe, G.W. Rebeck, C.E. Moussa, Parkin mediates beclin-dependent autophagic clearance of defective mitochondria and ubiquitinated Abeta in AD models, Hum. Mol. Genet. 20 (2011) 2091-2102.
[185] M. Martinez-Vicente, Z. Talloczy, E. Wong, G. Tang, H. Koga, S. Kaushik, R. de Vries, E. Arias, S. Harris, D. Sulzer, A.M. Cuervo, Cargo recognition failure is responsible for inefficient autophagy in Huntington's disease, Nat. Neurosci. 13 (2010) 567-576.

[186] T. Kawashima, Y. Inuzuka, J. Okuda, T. Kato, S. Niizuma, Y. Tamaki, Y. Iwanaga, A. Kawamoto, M. Narazaki, T. Matsuda, S. Adachi, G. Takemura, T. Kita, T. Kimura, T. Shioi, Constitutive SIRT1 overexpression impairs mitochondria and reduces cardiac function in mice, J. Mol. Cell. Cardiol. 51 (2011) 1026-1036. 